ROLE OF HEAT PIPES IN IMPROVING THE HYDROGEN CHARGING

RATE IN A METAL HYDRIDE STORAGE TANK

by

Yuzhu Liu

A thesis submitted to the Faculty of the University of Delaware in partial fulfillment of the requirements for the degree of Master of Science in Mechanical Engineering

Spring 2014

(C) 2014 Yuzhu Liu

All Rights Reserved 


\begin{abstract}
All rights reserved
INFORMATION TO ALL USERS

The quality of this reproduction is dependent upon the quality of the copy submitted.

In the unlikely event that the author did not send a complete manuscript and there are missing pages, these will be noted. Also, if material had to be removed,

a note will indicate the deletion.
\end{abstract}

UMI 1562395

Published by ProQuest LLC (2014). Copyright in the Dissertation held by the Author.

Microform Edition (c) ProQuest LLC.

All rights reserved. This work is protected against

unauthorized copying under Title 17, United States Code

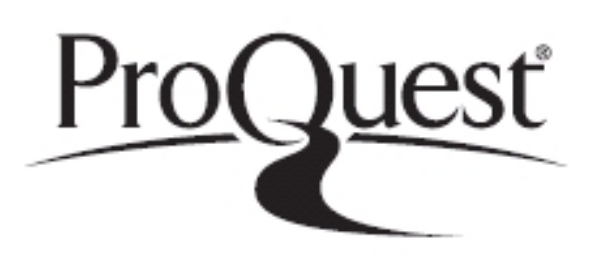

ProQuest LLC.

789 East Eisenhower Parkway

P.O. Box 1346

Ann Arbor, Ml $48106-1346$ 


\title{
ROLE OF HEAT PIPES IN IMPROVING THE HYDROGEN CHARGING RATE IN A METAL HYDRIDE STORAGE TANK
}

\author{
by
}

Yuzhu Liu

Approved:

Ajay K. Prasad, Ph.D.

Professor in charge of thesis on behalf of the Advisory Committee

Approved:

Suresh G. Advani, Ph.D.

Professor in charge of thesis on behalf of the Advisory Committee

Approved:

Suresh G. Advani, Ph.D.

Chair of the Department of Mechanical Engineering

Approved:

Babatunde A. Ogunnaike, Ph.D.

Dean of the College of Engineering

Approved:

James G. Richards, Ph.D.

Vice Provost for Graduate and Professional Education 


\section{ACKNOWLEDGMENTS}

I would like to express my deepest gratitude to my advisors, Dr. Ajay Prasad and Dr. Suresh Advani, for their professional guidance and support during my graduate study in University of Delaware. They offered me a great opportunity to work with intelligent people as well as thinking in an independent and creative way, which is a fortune for my whole life. I would also like to show my appreciation to my committee member, Dr. Andrew Goudy, for his participation and support.

A great thank you is also given to Hui Wang for his general knowledge on hydrogen storage, experiments, numerical modeling and paper writing as well as his generous help for every problem I encountered during various stages of my research.

I would like to thank my parents, Zhemin and Xinguo, for their continuous understanding and support, and also my boyfriend Howard Yang for his love as well as technical help on MATLAB and heat transfer.

I owe my thanks to all those people who have made this thesis possible and my study and research experience enjoyable. Special thanks to the Department of Mechanical Engineering, the Fuel Cell Research Lab, and the Federal Transit Administration and Department of Energy for funding me throughout my graduate study. 


\section{TABLE OF CONTENTS}

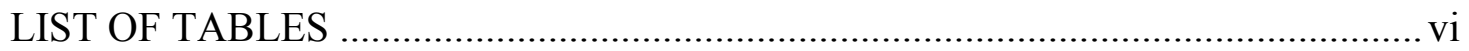

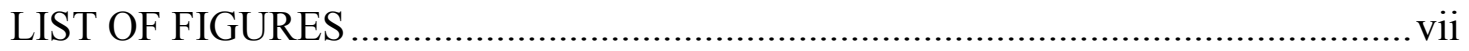

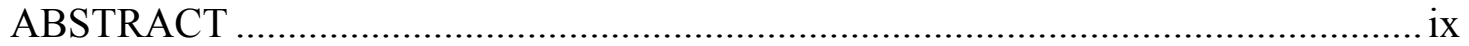

Chapter

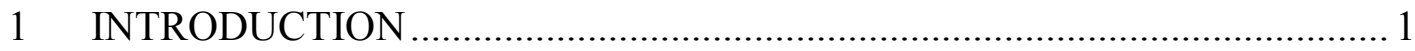

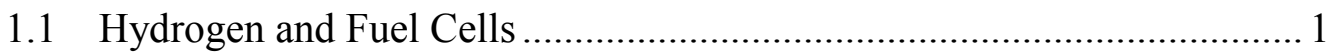

1.2 Metal Hydride-based Hydrogen Storage ....................................................... 4

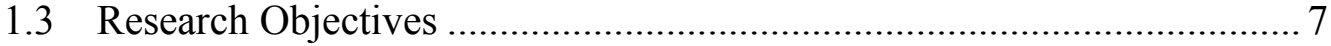

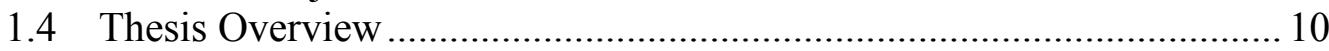

2 HYDROGEN STORAGE TANK MODELING …............................................... 11

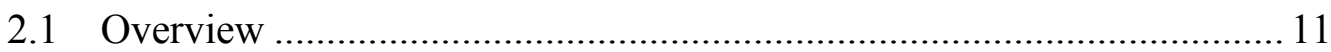

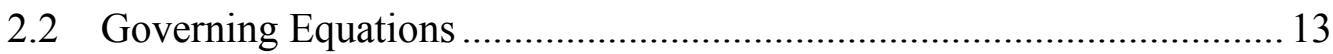

2.3 Initial and Boundary Conditions …………………............................. 15

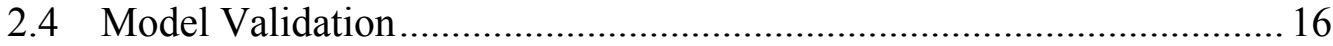

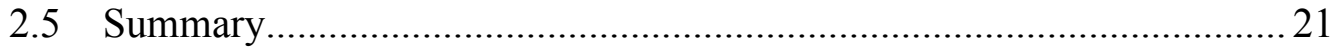

3 PARAMETRIC STUDY OF HYDROGEN STORAGE TANK …………...... 22

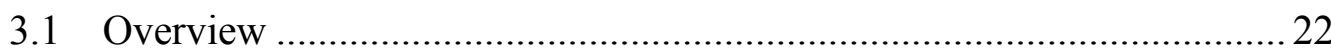

3.2 Determination of Parameter Range ………………............................... 22

3.3 Effect of Convective Heat Transfer Coefficient of Heat Pipe..................2 24

3.4 Effect of Convective Heat Transfer Coefficient of the Water Jacket......25

3.5 Effect of Water Jacket Temperature ........................................................ 26

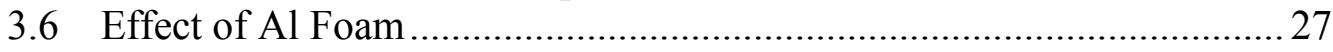

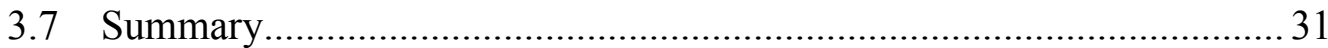

4 OPTIMIZATION STUDY FOR HEAT PIPE PLACEMENT IN LARGE

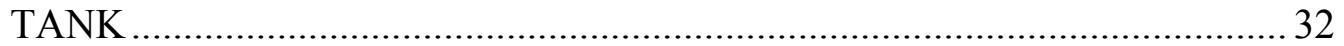

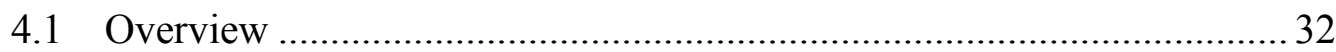

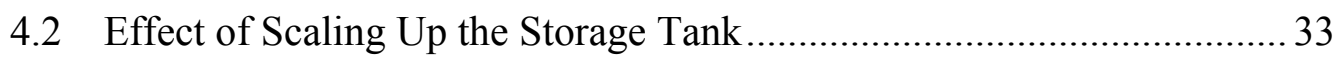

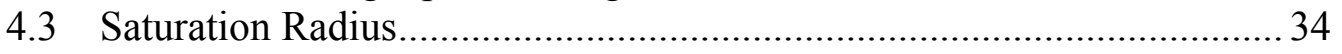


4.4 Role of Number and Location of Heat Pipes to Reduce Filling Time .... 43

4.4.1 Optimization Study without Al Foam ..................................... 45

4.4.2 Optimization Study with Al Foam ........................................... 48

4.4.3 Optimization Study for Varying Tank Size without Al Foam .... 50

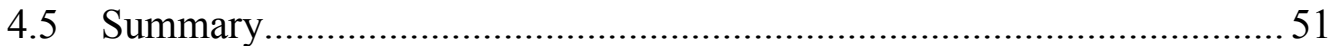

$5 \quad$ CONCLUSIONS AND FUTURE WORK ................................................. 53

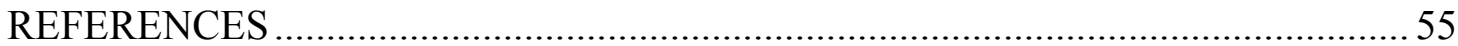




\section{LIST OF TABLES}

Table 1 - Properties of common metal hydrides .............................. 5

Table 2 - Baseline values for parameters and the ranges considered ................23

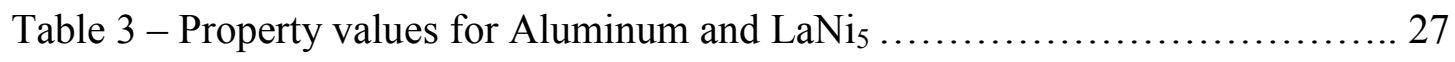

Table 4 - Ten minutes saturation radius for varying heat pipe sizes .............. 41

Table 5 - Number of heat pipes of $10 \mathrm{~mm}$ radius and mass of stored hydrogen in 10 minutes with different amounts of $\mathrm{Al}$ foam .................... 43

Table 6 - Heat pipe radius for one, two, three and four heat pipes $\quad \ldots \ldots \ldots \ldots \ldots \ldots 44$

Table 7 - Optimal charging time for one, two, three and four heat pipes ........... 48 


\section{LIST OF FIGURES}

Figure 1 - Schematic of a typical acid electrolyte fuel cell .................................... 2

Figure 2 - Experimental apparatus for hydrogen storage tank incorporating a heat pipe reproduced from Chung et al [24] with permission (NO. 3344340659194) from Elsevier 7

Figure 3 - Mathematical model of hydrogen storage tank (a) with heat pipe; (b) without heat pipe.

Figure 4 - Heat transfer characteristics of a heat pipe reproduced with permission from Elsevier [24] ................................................................. 18

Figure 5 - Weight percent of hydrogen absorbed vs. charging time by simulation..... 19

Figure 6 - Weight percent of hydrogen absorbed vs. charging time by experiment reproduced with permission from Elsevier [24]....

Figure 7 - Charging time for $90 \%$ hydrogen saturation of the tank as a function of convective heat transfer coefficient of the heat pipe

Figure 8 - Charging time for $90 \%$ hydrogen saturation of the tank as a function of convective heat transfer coefficient of the water jacket....

Figure 9 - Charging time for $90 \%$ hydrogen saturation of the tank as a function of the water jacket temperature.

Figure 10 - Effective property values of metal hydride/Al foam mixture: (a) thermal conductivity; (b) heat capacity; (c) material density.

Figure 11 - Effect of Al foam content on saturation time for varying convective heat transfer coefficient of the heat pipe 30

Figure 12 - Effect of Al foam content on saturation time for varying convective heat transfer coefficient of the cooling water jacket 30

Figure 13 - Weight percent of hydrogen absorbed vs. charging time in a large tank containing $280 \mathrm{~kg}$ of metal hydride. 
Figure 14 - Computational mesh for storage tank to study hydrogen saturation dynamics in the neighborhood of the heat pipe

Figure 15 - Saturation radius (radius of the region with $90 \%$ saturation) for varying Al foam content ( 0 to $40 \%$ ) at various time intervals for different heat pipe radii. (a) $3 \mathrm{~mm}$, (b) $5 \mathrm{~mm}$, (c) $7 \mathrm{~mm}$, (d) $10 \mathrm{~mm}$

Figure 16 - Contour plots of saturation at $7 \mathrm{~min}$ for a $3 \mathrm{~mm}$ heat pipe with varying amounts of $\mathrm{Al}$ foam: (a) $0 \%$; (b) $5 \%$; (c) $10 \%$; (d) $20 \%$; (e) $30 \%$; and (f) $40 \%$.

Figure 17 - Hydrogen saturation as a function of tank radius for a $3 \mathrm{~mm}$ heat pipe at 7 minutes, with $\mathrm{Al}$ foam content ranging from 0 to $40 \%$

Figure 18 - Geometry of hydrogen storage tank of $100 \mathrm{~mm}$ radius incorporating one heat pipe of $10 \mathrm{~mm}$ radius

Figure 19 - Normalized $90 \%$ saturation time for different positions of $10 \mathrm{~mm}$ heat pipes in a tank of $100 \mathrm{~mm}$ radius; (a) two heat pipes; (b) three heat pipes; (c) first configuration with four heat pipes; (d) second configuration with four heat pipes

Figure 20 - Normalized 90\% saturation time for different arrangements of heat pipes with (a) $5 \%$, and (b) $10 \% \mathrm{Al}$ foam. For the four heat pipe case, only the square topology was employed

Figure 21 - Normalized 90\% saturation time for four heat pipes in a square topology in a tank of radius (a) $50 \mathrm{~mm}$, and (b) $25 \mathrm{~mm}$ 


\begin{abstract}
Metal hydrides can store hydrogen at high volumetric efficiencies. As the process of charging hydrogen into a metal powder to form its hydride is exothermic, the heat released must be removed quickly to maintain a rapid charging rate. An effective heat removal method is to incorporate a heat exchanger such as a heat pipe within the metal hydride bed. In this paper, we describe a two-dimensional axisymmetric study to predict the transient heat and mass transfer in a cylindrical metal hydride tank embedded with one or more heat pipes. Results from a parametric study of hydrogen storage efficiency are presented as a function of storage tank size, water jacket temperature and its convective heat transfer coefficient, and heat pipe radius and its convective heat transfer coefficient. The effect of enhancing the thermal conductivity of the metal hydride by adding aluminum foam is also investigated. The study reveals that the cooling water jacket temperature and the heat pipe's heat transfer coefficient are most influential in determining the heat removal rate. The addition of aluminum foam reduces the filling time as expected. For larger tanks, more than one heat pipe is necessary for rapid charging. It was found that using more heat pipes of smaller radii is better than using fewer heat pipes with larger radii. The optimal distribution of multiple heat pipes was also determined and it is shown that their relative position within the tank scales with the tank size.
\end{abstract}




\section{Chapter 1}

\section{INTRODUCTION}

\subsection{Hydrogen and Fuel Cells}

Over the past centuries, fossil fuels such as coal, oil, and gas, have been widely used to generate power for every aspect of our daily life. Although conventional energy is cheap and convenient, it also leads to severe problems. The combustion of fossil fuels releases gases, including $\mathrm{SO}_{x}, \mathrm{NO}_{x}$, and $\mathrm{CO}_{\mathrm{x}}$, as well as particulates, which results in air pollution and the consequential environmental damage. The release of $\mathrm{SO}_{\mathrm{x}}$ in the air is the main cause of local effects such as acid rain, whereas the emission of $\mathrm{CO}_{2}$ causes global effects such as the rise of the earth's surface temperature known as the "Greenhouse Effect". The emission of particulates in the air also triggers respiratory disease among people. In addition to their adverse impacts on the environment and health, fossil fuels are also non-renewable. Fossil fuels need millions of years to form, whereas their consumption rate has been extremely rapid with increasing industrial development. This imbalance between supply and demand will inevitably lead to resource depletion. Due to these drawbacks of conventional energy sources, it is critical to explore new energy sources that are both renewable and environmentally friendly.

Hydrogen is considered a clean fuel and has received a lot of attention in recent years. Hydrogen can be produced, for example, by electrolyzing water using solar electricity [1], which represents a renewable pathway for fuel production. A fuel cell can then be used to convert the chemical energy of hydrogen directly into 
electrical energy. The fuel cell reaction is shown in Figure 1 [2]. It is evident that the only byproduct of the fuel cell reaction is water. Therefore, fuel cells represent a renewable and environmentally-friendly power source.

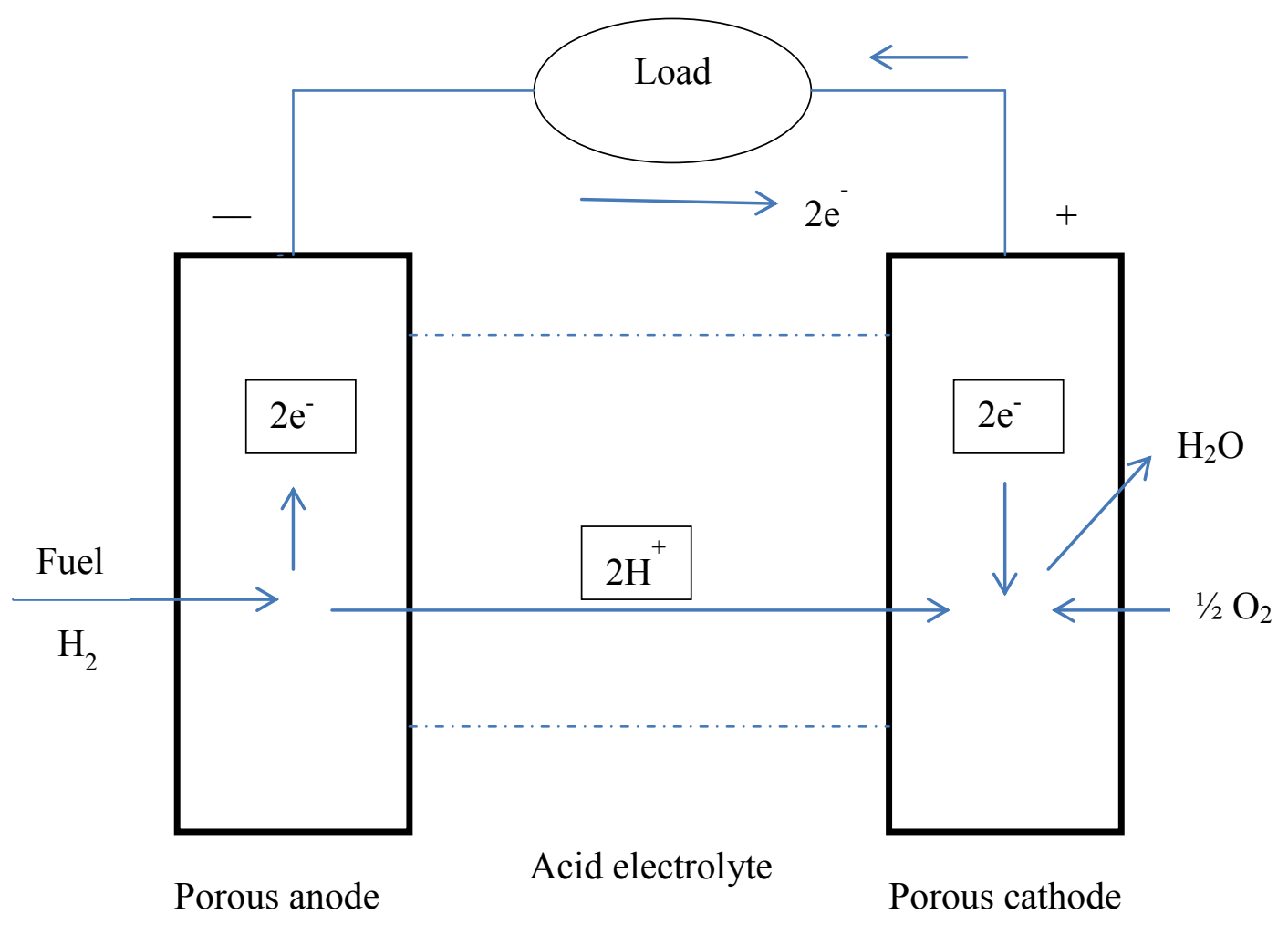

Figure 1 - Schematic of a typical acid electrolyte fuel cell

Although fuel cells have demonstrated their potential as a clean and efficient power source, hydrogen storage remains a major challenge, especially for automotive applications. Hydrogen is a flammable and explosive gas, so careful attention must be paid to the design of a safe and effective storage system. An important consideration 
for hydrogen powered cars is that customers would demand short refilling times. Hence it is vital to find a way the charge hydrogen into a storage tank in a short time. Moreover, the gravimetric and volumetric storage density of the hydrogen storage tank should be as high as possible, particularly for automotive applications. The US Department of Energy (DOE) has published targets for onboard hydrogen storage systems for light-duty vehicles [3] which include safety, recharge rate, and gravimetric and volumetric efficiencies.

Several studies have been conducted on the method of hydrogen storage [4-7]. One conventional method is to store hydrogen as a compressed gas (typically at 350 to 700 bar). To tolerate the high pressure, the tank wall needs to be very thick and strong, which increases the weight of the hydrogen storage tank. Most compressed hydrogen storage tanks employ composite materials to reinforce the tank, however, the manufacturing process can be time consuming and costly. Furthermore, compressed hydrogen represents a hazard due to the possibility of a high-pressure leak. Another method is to liquefy hydrogen and store it as a cryogenic liquid. However, the liquefaction of hydrogen is extremely energy intensive and the required cryogenic tanks are also very expensive and bulky. Thus the total volume and weight of the system is increased. Carbonaceous materials such as carbon nanotubes were also studied to provide a new method to store hydrogen. It was suggested that hydrogen could be absorbed into the pores of single-walled carbon nanotubes at extremely high storage densities. Unfortunately, experimental studies and numerical investigations have shown that it is not possible to meet the required DOE targets with these materials [8]. 
Metal hydrides are a promising option for hydrogen storage. Hydrogen reacts with certain metals or their alloys to form metal hydrides at moderate pressures (10 bar) and with surprisingly high storage densities. Hence, concerns about leaks are

mitigated, and the system does not require sophisticated insulation as in the case of liquid hydrogen. Metal hydride systems can also provide a higher hydrogen storage density and hence the volumetric and gravimetric efficiencies are improved. The stored hydrogen can be easily released for use by simply heating the hydride bed. These advantages have made metal hydride-based hydrogen storage a topic of ongoing research.

\subsection{Metal Hydride-based Hydrogen Storage}

Different types of metal hydride materials have been studied to date and the main categories include Mg-based metal hydrides, complex hydrides and intermetallic compounds.

Magnesium and its alloys have attracted a lot of research recently due to its high gravimetric efficiency and low cost [7]. However, the practical issue with $\mathrm{Mg}$ based metal hydrides is that it needs high environmental temperatures to desorb hydrogen and the rate of absorption is very low. Complex hydrides, such as sodium, lithium, and beryllium are also potential materials for hydrogen storage. They are lighter than $\mathrm{Mg}$, so the hydrogen storage system weight would be further reduced. Hydrogen evolves upon contact with water in this complex hydride storage system which includes common materials such as sodium, lithium and potassium alanates, lithium nitrides, lithium borohydride, and beryllium hydrides. However, they all require high temperatures to react. Lanthanum-nickel $\left(\mathrm{LaNi}_{5}\right)$, which reacts at room 
temperature, has become the most popular intermetallic compounds material used for hydrogen storage, although its low storage capacity of only about 1.5 weight percent is a disadvantage. The properties of commonly used metal hydride materials are summarized in Table 1.

Table 1 - Properties of common metal hydrides

\begin{tabular}{|c|c|c|c|c|}
\hline Material & $\begin{array}{c}\text { Temperature } \\
\left({ }^{\circ} \mathrm{C}\right)\end{array}$ & $\begin{array}{l}\text { Weight } \\
\text { percent }\end{array}$ & Advantage & Disadvantage \\
\hline Mg-based & 300 & $7.6 \%$ & $\begin{array}{l}\text { Low cost, high } \\
\text { storage capacity }\end{array}$ & $\begin{array}{l}\text { High temperature, } \\
\text { slow kinetics }\end{array}$ \\
\hline $\mathrm{NaAlH}_{4}$ & 260 & $7.4 \%$ & $\begin{array}{l}\text { Low cost, high } \\
\text { storage capacity }\end{array}$ & $\begin{array}{l}\text { High temperature, } \\
\text { slow kinetics }\end{array}$ \\
\hline $\mathrm{LiAlH}_{4}$ & $160-220$ & $11.0 \%$ & $\begin{array}{c}\text { High storage } \\
\text { capacity }\end{array}$ & $\begin{array}{l}\text { High temperature, } \\
\text { slow kinetics }\end{array}$ \\
\hline $\mathrm{KAlH}_{4}$ & $250-330$ & $3.5 \%$ & Fast reaction & Low storage capacity \\
\hline $\begin{array}{l}\text { Lithium } \\
\text { nitrides }\end{array}$ & $230-270$ & $7.0 \%$ & $\begin{array}{l}\text { High storage } \\
\text { capacity }\end{array}$ & $\begin{array}{c}\text { High temperature } \\
\mathrm{NH}_{3} \text { release }\end{array}$ \\
\hline $\mathrm{LiBH}_{4}$ & 470 & $18 \%$ & $\begin{array}{l}\text { High storage } \\
\text { capacity }\end{array}$ & $\begin{array}{l}\text { High temperature, } \\
\text { slow kinetics }\end{array}$ \\
\hline $\mathrm{Li}_{3} \mathrm{Be}_{2} \mathrm{H}_{7}$ & 150 & $8 \%$ & $\begin{array}{l}\text { High storage } \\
\text { capacity, } \\
\text { lightweight }\end{array}$ & Highly toxic \\
\hline $\mathrm{LaNi}_{5}$ & 20 & $1.5 \%$ & Low temperature & Low storage capacity \\
\hline
\end{tabular}

From Table 1, we can see most metal hydrides have high storage capacity and can meet the DOE requirement. However, slow kinetics is a big concern. The ultimate DOE target for filling time for $5 \mathrm{~kg}$ hydrogen is $2.5 \mathrm{~min}$, whereas most of the metal hydride materials need several hours. The reason is that metal hydriding is an exothermic process, in which substantial of heat of reaction is generated. As a result the temperature of the hydride bed rises due to the poor conductivity of metal hydride. 
At elevated temperatures, the hydriding rate reduces, and it takes a long time to completely saturate the hydride bed with hydrogen. Hence it is critically important to remove the heat of the reaction rapidly from the hydride bed. Thus, to meet the DOE target, the heat transfer problem inside the metal hydride tank must be solved.

Both numerical analysis and experimental research have been conducted in previous studies to address effective heat removal from metal hydride beds during charging. Mathematical models of transient heat and mass transfer have been created and the effect of heat transfer on reaction rate has been evaluated [9-13]. They reveal that enhancing the heat transfer rate is an important requirement to reduce filling time. Several methods have been developed to increase the heat removal rate. For example, aluminum and nickel foam have been added to the metal hydride material in order to enhance its effective heat conductivity [14-15], and the optimal content of aluminum was studied [16]. Another popular method is incorporating heat exchangers, such as a plate-fin exchanger [17], or a helical coil and their optimization [18-20].

Recently a new type of heat exchanger, the heat pipe, has been studied [21-22]. A heat pipe is a device that transfers heat very effectively through liquid-vapor phase change. Boo et al [23] and Chung et al [24] showed that incorporating heat pipes in a metal hydride tank substantially improved the hydrogen filling rate by simulation and experiment. In the study by Chung et al [24], the filling rates in two identical hydride tanks with and without heat pipes were compared. The experimental setup of the system is shown in Figure 2. The entire tank was submerged into a water bath, which removes heat from the tank wall by natural convective. The heat pipe incorporated in the center of tank removed heat by liquid-vapor phase change with a very high convective heat transfer coefficient. Both these pathways enhanced heat removal and 
reduced the hydrogen filling time. The results confirmed the significant effect of introducing a heat pipe into the hydride tank which not only increased the heat removal rate during absorption but also maintained a stable hydrogen supply during desorption.

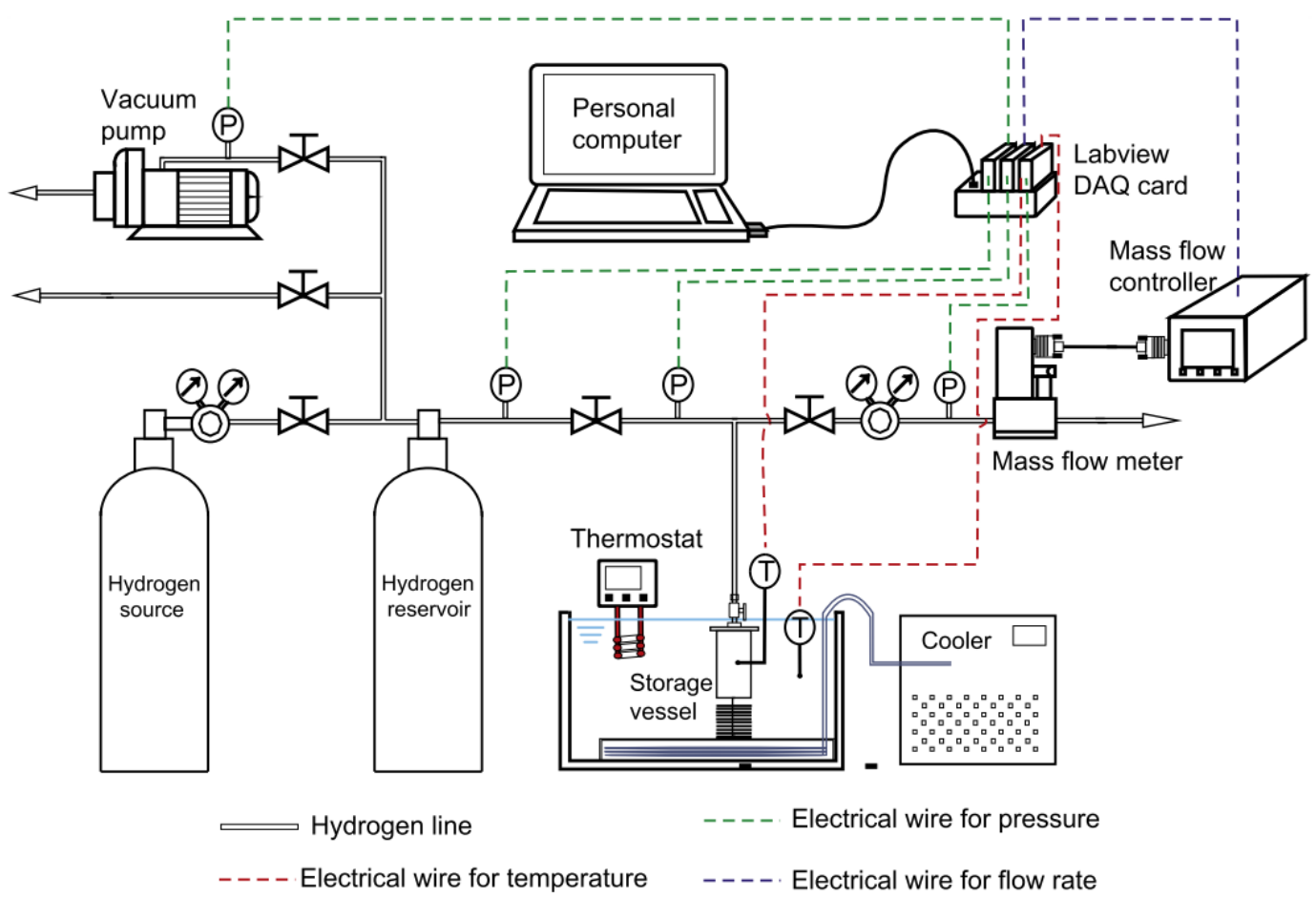

Figure 2 - Experimental apparatus for hydrogen storage tank incorporating a heat pipe reproduced from Chung et al [24] with permission (NO. 3344340659194) from Elsevier

\subsection{Research Objectives}

The incorporation of heat pipes represents a promising new method to improve the heat removal rate in the hydrogen storage tank. Before implementation, several parameters must be considered such as the number and location of heat pipes, the heat 
pipe radius, and its heat transfer coefficient. In addition, the tank can be surrounded by a water bath whose temperature and heat transfer coefficient can also be varied.

In the experiment conducted by Chung et al. [24], only one type of heat pipe was used, however, in practice, heat pipes exist in different sizes and heat transfer capacities. In this thesis we will investigate different types and sizes of heat pipes by changing the convective heat transfer coefficient and the radii of the heat pipe, as well as their number and relative position within the hydride bed. Heat extraction by the active cooling with a water jacket will also be addressed by varying the ambient temperature of the water jacket and/or changing its heat transfer coefficient. The water jacket could be replaced with a passive system such as a water bath, hence the effect of natural convective on the filling rate will also be investigated.

The low thermal conductivity of the metal hydride is also a rate-limiting factor when a convective cooling boundary condition is applied on the walls of the storage tank (the water jacket). A heat pipe located along the centerline of the cylinder will help to remove heat quickly from the metal hydride surrounding the heat pipe, but once the hydride bed in the immediate vicinity of the heat pipe is saturated, further heat removal from regions that are not close to the center or the cylinder walls depends on the thermal conductivity of the medium. Addition of aluminum foam to the metal hydride will increase its effective thermal conductivity. The addition of aluminum foam would change the metal hydride material's properties such as specific heat and heat conductivity; the amount of change would depend on the amount of added Al. The downside of adding $\mathrm{Al}$ is that the $\mathrm{Al}$ foam displaces metal hydride from the tank which reduces the active volume inside the tank, and reduces its volumetric hydrogen 
storage density. Thus, an optimization study could be conducted to determine the optimal amount of $\mathrm{Al}$ foam to be added to the tank.

For automotive applications, DOE has specified a tank that can store $5 \mathrm{~kg}$ of hydrogen. Therefore, the tank size is another parameter that needs to be considered. It is obvious that, in a large tank, only one heat pipe located at its center could not remove heat effectively. Thus, a large hydrogen storage tank would require the incorporation of multiple heat pipes. This leads to the question of how best to arrange these heat pipes for maximum effectiveness.

Thus it is worthwhile to conduct a parametric study to fully understand the effect of incorporating one or more heat pipes into the hydrogen storage tank and investigating the role of various parameters, including the heat pipe radius and its convective heat transfer coefficient, water jacket temperature and its convective heat transfer coefficient, $\mathrm{Al}$ foam content, and the number and configuration of multiple heat pipes in larger tanks. The study will be performed using commercially available software: Gambit and Ansys Fluent. The heat pipe is modeled by prescribing a high convective heat transfer coefficient at its inner surface. The convective coefficient can be set along the outer boundary of the tank to represent natural or forced convection by the surrounding water jacket. We will also simulate cases with varying $\mathrm{Al}$ foam content by changing the thermophysical values of the hydride material such as thermal conductivity and heat capacity. The goal would be to isolate the role of each parameter mentioned above and identify which parameter or parameters significantly influence the filling rate. This exercise will provide design guidelines for fabricating hydrogen storage systems with metal hydrides. The metal hydride material used in this study is 
$\mathrm{LaNi}_{5}$, which reacts at room temperature, so that the numerical results could be easily validated through experiment in a future study.

\subsection{Thesis Overview}

The goal of this study is to numerically evaluate the effect of different parameters that may change the hydrogen filling time for a metal hydride-based hydrogen storage tank incorporating one or more heat pipes. Chapter 2 describes a coupled kinetics and heat transfer mathematical model used to study this problem along with the boundary and initial conditions. The hydrogen storage tank with and without heat pipes was simulated using GAMBIT and Ansys Fluent and validated against the experimental results of Chung et al. [24]. Chapter 3 describes the parametric study to evaluate the effect of convective heat transfer coefficient, water jacket temperature, Al foam content and tank size. Chapter 4 focuses on an optimization study on a large hydrogen storage tank incorporating multiple heat pipes and provides guidelines for the optimal location of the heat pipes. Finally, a summary of this parametric study and the possible future work are presented in Chapter 5 . 


\section{Chapter 2}

\section{HYDROGEN STORAGE TANK MODELING}

\subsection{Overview}

Conducting an experimental parametric study on the effect of heat pipes on the filling rate in a hydride-based hydrogen storage tank by varying the heat pipe radius and its convective heat transfer coefficient, water jacket temperature and its convective heat transfer coefficient, Al foam content, and the number and configuration of multiple heat pipes would be extremely time-consuming and prohibitively expensive. On the other hand, computer modeling and simulation represent a very cost-effective alternative. Simulations are a necessary first step that can provide valuable insight into whether the actual experiment is worthwhile.

Ansys Fluent 14.0 was used to develop and solve the mathematical model [25]. Ansys Fluent is a powerful, commercially available computational fluid dynamics (CFD) tool which solves complex fluid flow, heat transfer, and reaction kinetics problems in a user-friendly manner [26]. GAMBIT was used in this study as the preprocessing software to establish the model of the hydrogen storage tank [27]. It is also a commercially available software package. A physical model of the hydrogen storage tank was designed using GAMBIT and the corresponding boundary conditions and zone distribution were defined. The discretized mesh was also constructed in GAMBIT and provided as an input to Ansys Fluent which solved the relevant governing equations. The equations for the mathematical model of heat transfer are determined and compiled as user defined functions (Udf) in Ansys Fluent. Ansys 
Fluent then uses the Udfs along with the boundary and initial conditions to compute the solution which can either be plotted directly or exported for further analysis.

This mathematical model evaluated the transient heat and mass transfer in the hydrogen storage tank, as a function of the heat pipe radius, convective coefficient of the heat pipe and the water jacket, water jacket temperature, and effective thermal conductivity of the metal hydride material. A similar mathematical model was used in previous work by our group to investigate a hydrogen storage tank with enhanced thermal conductivity metal hydride material [16] and a helical-coil heat exchanger [18]. Although this model employs certain assumptions to simplify the simulations, they have been successfully validated by comparing against experiment results.

The heat pipe provides a high convective heat transfer coefficient by liquidvapor phase change inside the heat pipe. Hence the heat pipe is modeled here by prescribing a high convection coefficient at its inner surface. The use of Al foam to enhance the thermal conductivity of the hydride bed can also be easily modeled by simply prescribing a suitably high thermal conductivity to the hydride material.

The following assumptions were made in the model:

1. Hydrogen in the tank is regarded as an ideal gas.

2. Pressure variations in the tank are ignored.

3. Radiative heat transfer is neglected.

4. Thermal and physical properties of the material are independent of hydrogen concentration and temperature.

5. Local thermal equilibrium is attained instantly between the metal hydride material and hydrogen gas.

6. The advection transport term is ignored. 
7. All effective properties, including the effective thermal conductivity of the metal hydride/Al foam mixture, are calculated using numerical method [16].

8. Heat transfer into the heat pipe is quantified by specifying a convective heat transfer coefficient, and the actual phase-change process inside the heat pipe is ignored.

The heat diffusion equation, mass balance and mass absorption equations are solved for $\mathrm{LaNi}_{5}$ metal hydride material.

The accuracy of this model must be clearly established before commencing a detailed parametric study. Here, we used the experimental results of Chung et al. [24] to validate our model.

In this chapter, we first introduce the mathematical equations that will be used to solve the heat transfer problem of hydrogen storage followed by the initial and boundary conditions. Next, we present a validation of the model by comparing the results of the simulation with the experimental results of Chung et al. [24].

\subsection{Governing Equations}

For an axisymmetric tank containing the metal hydride material, the energy conservation can be expressed as:

$\left(\rho C_{\mathrm{p}}\right)_{\mathrm{eff}} \frac{\partial T}{\partial t}=\frac{1}{r} \frac{\partial}{\partial r}\left(r k_{\mathrm{eff}} \frac{\partial T}{\partial t}\right)+\frac{\partial}{\partial z}\left(k_{\mathrm{eff}} \frac{\partial T}{\partial z}\right)-m_{\mathrm{abs}}\left(\Delta H^{\circ}+T\left(C_{\mathrm{pg}}-C_{\mathrm{ps}}\right)\right)$

where $\left(\rho C_{\mathrm{p}}\right)_{\mathrm{eff}}$ is the volume-averaged heat capacity of hydrogen and metal hydride, $k_{\text {eff }}$ is the effective thermal conductivity, $m_{\mathrm{abs}}$ is the rate of hydrogen absorbed per 
unit volume, $\Delta H^{\circ}$ is the heat of the reaction, and $C_{\mathrm{pg}}$ and $C_{\mathrm{ps}}$ represent the specific heats for hydrogen and the metal hydride material, respectively.

The dispersed system of metal hydride powder is a porous medium, thus one can use Darcy's law to compute the average velocity of hydrogen, $v_{\mathrm{g}}$, in the tank as follows:

$$
v_{\mathrm{g}}=-\frac{K}{\mu_{\mathrm{g}}} \nabla P_{\mathrm{g}}
$$

Here $K$ is the permeability of the metal hydride, $\mu_{\mathrm{g}}$ is the dynamic viscosity of the hydrogen, and $P_{\mathrm{g}}$ is the hydrogen pressure.

The mass conservation equation for hydrogen can be written as:

$$
\varepsilon \frac{\partial\left(\rho_{\mathrm{g}}\right)}{\partial t}+\nabla \cdot\left(\rho_{\mathrm{g}} v_{\mathrm{g}}\right)=-m_{\mathrm{abs}}
$$

where $\varepsilon$ is the porosity of the medium, $\rho_{\mathrm{g}}$ is the density of hydrogen, and $m_{\mathrm{abs}}$ can be described by the constitutive equation:

$$
m_{\mathrm{abs}}=-C_{\mathrm{a}} \exp \left(-\frac{E_{\mathrm{a}}}{R_{\mathrm{g}} T}\right) \ln \left(\frac{P_{\mathrm{g}}}{P_{\mathrm{eq}}}\right)\left(\rho_{\mathrm{s}}-\rho\right)
$$

where $C_{\mathrm{a}}$ is the absorption constant, $E_{\mathrm{a}}$ is the activation energy for absorption, $R_{\mathrm{g}}$ is the gas constant, $T$ is the temperature in $\mathrm{K}$, and $\rho_{\mathrm{s}}$ is the saturation density of the metal hydride material. The Van't Hoff relationship can be used here to compute the equilibrium pressure for absorption, $P_{\text {eq }}[28]$ :

$$
\ln \frac{P_{e q}}{1000}=A-\frac{B}{T}
$$

Here $A$ and $B$ are constants and depend on the hydride material. For $\mathrm{LaNi}_{5}, A$ and $B$ are 17.608 and 3704.6, respectively [29]. 
The above equations are solved with Ansys Fluent. In Fluent, we create the finite element mesh of the tank, specify the material properties, and boundary and initial conditions. Next, Fluent uses the finite volume method to solve the governing partial differential equations (Eqs. 1-3) on a finite element mesh. We introduce userdefined functions within Fluent to couple constitutive equations (4) and (5) with mass and energy conservation (Eqs. 1 and 3) and Darcy's law (Eq. 2).

\subsection{Initial and Boundary Conditions}

The hydrogen inlet is placed at the center of the top endplate of the cylindrical tank, and heat is extracted by the embedded heat pipe and by the water jacket surrounding the tank. The geometry and the prescribed convective boundary conditions are shown in Figure 3. The heat flux through the heat pipe surface is:

$$
-k_{\mathrm{eff}} \nabla T \cdot \vec{n}=h_{\mathrm{p}}\left(T-T_{\mathrm{p}}\right)
$$

where $k_{\text {eff }}$ is the effective heat conductivity of the metal hydride, $\nabla T$ is the temperature gradient, $\vec{n}$ is the normal vector of the heat pipe surface, $h_{\mathrm{p}}$ is the heat convection coefficient of heat pipe, and $T$ and $T_{\mathrm{p}}$ are the temperature of the metal hydride and the heat pipe surface. When no heat pipe is incorporated, $h_{\mathrm{p}}$ is zero and the equation simplifies to:

$$
\nabla T \cdot \vec{n}=0
$$

The heat flux from the external wall of the tank is via natural convection:

$$
-k_{\mathrm{wall}} \nabla T \cdot \vec{n}=h_{\mathrm{w}}\left(T-T_{\mathrm{w}}\right)
$$

where $k_{\text {wall }}$ is the thermal conductivity of the material of the tank, $\vec{n}$ is the normal vector of the tank wall, $h_{\mathrm{w}}$ is the convective heat transfer coefficient of the water in 
the jacket with respect to the tank wall, and $T_{\mathrm{w}}$ is the temperature of the water jacket. When there is no water jacket enveloping the cylindrical tank, $h_{\mathrm{w}}=0$ and Eq. 8 reduces to Eq. 7.

The initial metal hydride density, pressure, and temperature are assumed to be uniform inside the tank and are set to:

$$
\rho_{\mathrm{s}}=\rho_{0}, P_{\mathrm{g}}=P_{0}, T=T_{0}
$$

\subsection{Model Validation}

a

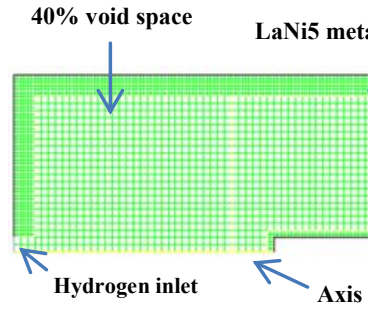

b

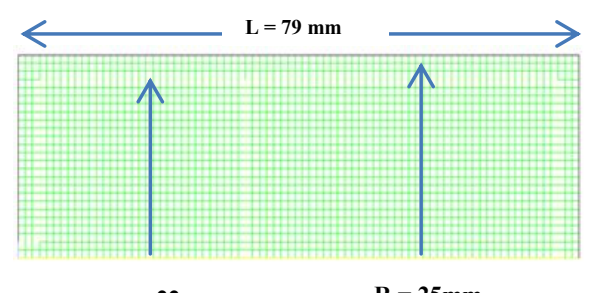

Tank is submerged in water, convective boundary $h=60 \mathrm{~W} / \mathrm{m} 2-\mathrm{K}, \mathrm{T}=295 \mathrm{~K}$

Figure 3 - Mathematical model of hydrogen storage tank (a) with heat pipe; (b) without heat pipe.

First we constructed the numerical model for the hydrogen storage tank with and without the heat pipe in GAMBIT as shown in Figure 3. The tank is set up as an axisymmetric cylinder with the heat pipe at its center and hydrogen inlet at the center 
of the top cover plate. Since we are validating our model against the experimental results of Chung et al. [24], we employed the identical tank geometry as theirs and used the same amount of metal hydride material $\left(280 \mathrm{~g}\right.$ of $\left.\mathrm{LaNi}_{5}\right)$.

The inner and outer diameters of the hydrogen storage tank are $44 \mathrm{~mm}$ and 50 $\mathrm{mm}$, respectively, and the height is $79 \mathrm{~mm}$ (the inside height is $73 \mathrm{~mm}$ ). The heat pipe in case (a) has a diameter of $6 \mathrm{~mm}$ and a height of $150 \mathrm{~mm}$. For $280 \mathrm{~g}$ of $\mathrm{LaNi}_{5}$, whose density and porosity are $8400 \mathrm{~kg} / \mathrm{m}^{3}$ and 0.5 , respectively, the volume and height occupied by the material in the tank are $0.067 \mathrm{~L}$ and $43.8 \mathrm{~mm}$. We embed $40 \mathrm{~mm}$ of the heat pipe inside the tank and the rest of its length is exposed to the water jacket. The water jacket temperature as given in Chung's paper is $20^{\circ} \mathrm{C}$. The hydrogen filling pressure is constant at 10 bar.

Next we need to select the values of parameters such as the heat convective coefficient of the heat pipe and water jacket. Chung's paper provides the heat transfer characteristics for their heat pipe as reproduced in Figure 4, which can be used to calculate the heat transfer coefficient, $h$, of this heat pipe. We know that

$$
\Delta T=Q \cdot R
$$

where $\Delta T$ is temperature difference, $Q$ is heat transfer rate and $R$ is thermal resistance. We also know that

$$
Q=h \cdot A \cdot \Delta T
$$

where A is surface area. Substituting Equation (10) into Equation (9), we get

$$
h=\frac{1}{R \cdot A}
$$

For a heat pipe with $6 \mathrm{~mm}$ diameter and $40 \mathrm{~mm}$ height inside the tank, the surface area is 


$$
A=2 \pi \cdot\left(\frac{6}{2}\right) \cdot 40+\pi \cdot\left(\frac{6}{2}\right)^{2}=781.86 \mathrm{~mm}^{2}
$$

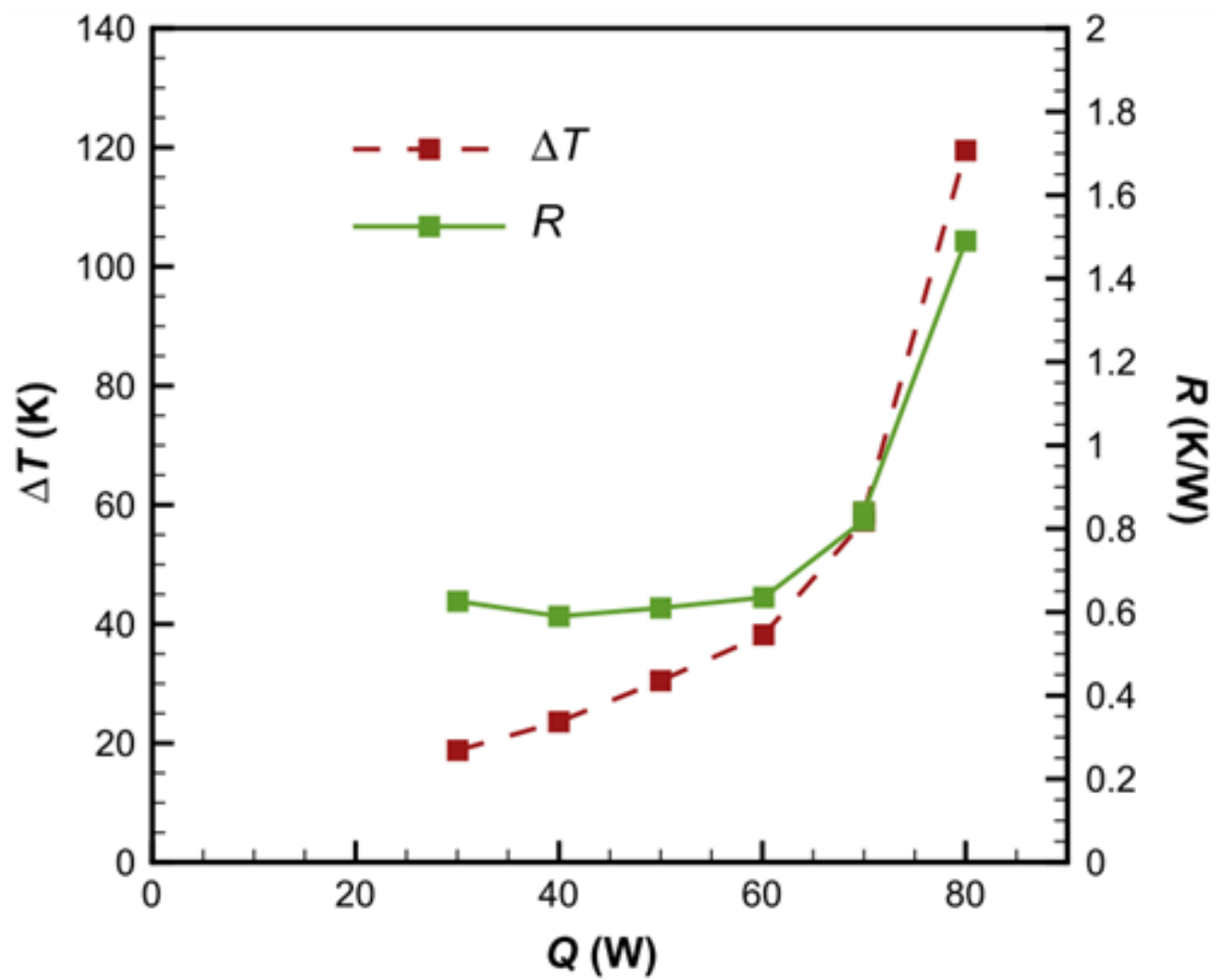

Figure 4 - Heat transfer characteristics of a heat pipe reproduced with permission from Elsevier [24]

Figure 4 shows that $R$ is nearly constant when $Q<60 \mathrm{~W}$ and increases dramatically for $Q>60 \mathrm{~W}$. To calculate the baseline h for our simulation, we decided to use the average $R$ of these six points, which is $R=0.783 \mathrm{~K} / \mathrm{W}$. Substituting the values of $A$ and $R$ into Equation (11) we obtain: 


$$
h=\frac{1}{0.783 \times 781.86 \times 10^{-6}}=1633.46 \frac{W}{m^{2} k}
$$

The natural convective heat transfer coefficient of the water jacket, is difficult to calculate exactly since the geometry of the tank and heat pipe is non-standard. Therefore, we decided to use a typical natural convective heat transfer coefficient of water for this simulation first and verify it by comparing it to the experimental result. Usually, the natural convective heat transfer coefficient for water ranges from 20 to $100 \mathrm{~W} / \mathrm{m}^{2} \mathrm{~K}$, thus the mid-range value of $60 \mathrm{~W} / \mathrm{m}^{2} \mathrm{~K}$ was used first for our simulation.

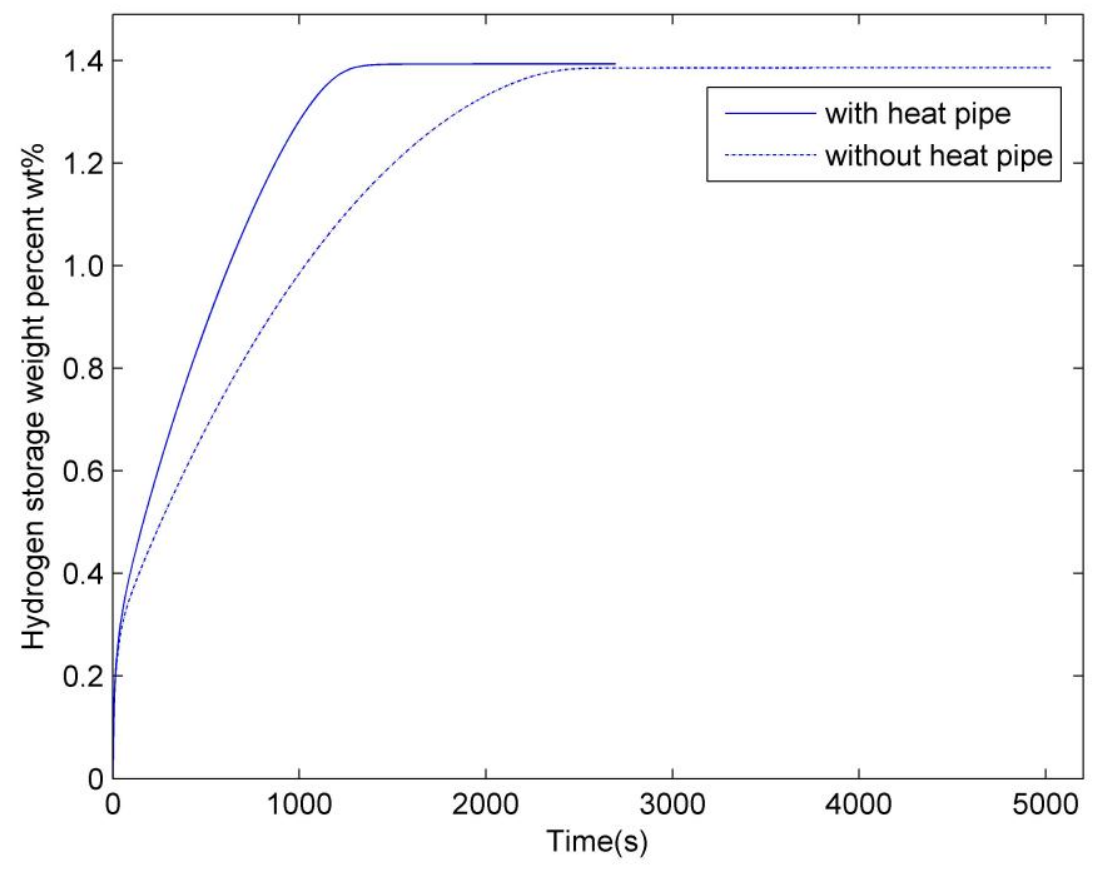

Figure 5 - Weight percent of hydrogen absorbed vs. charging time by simulation 


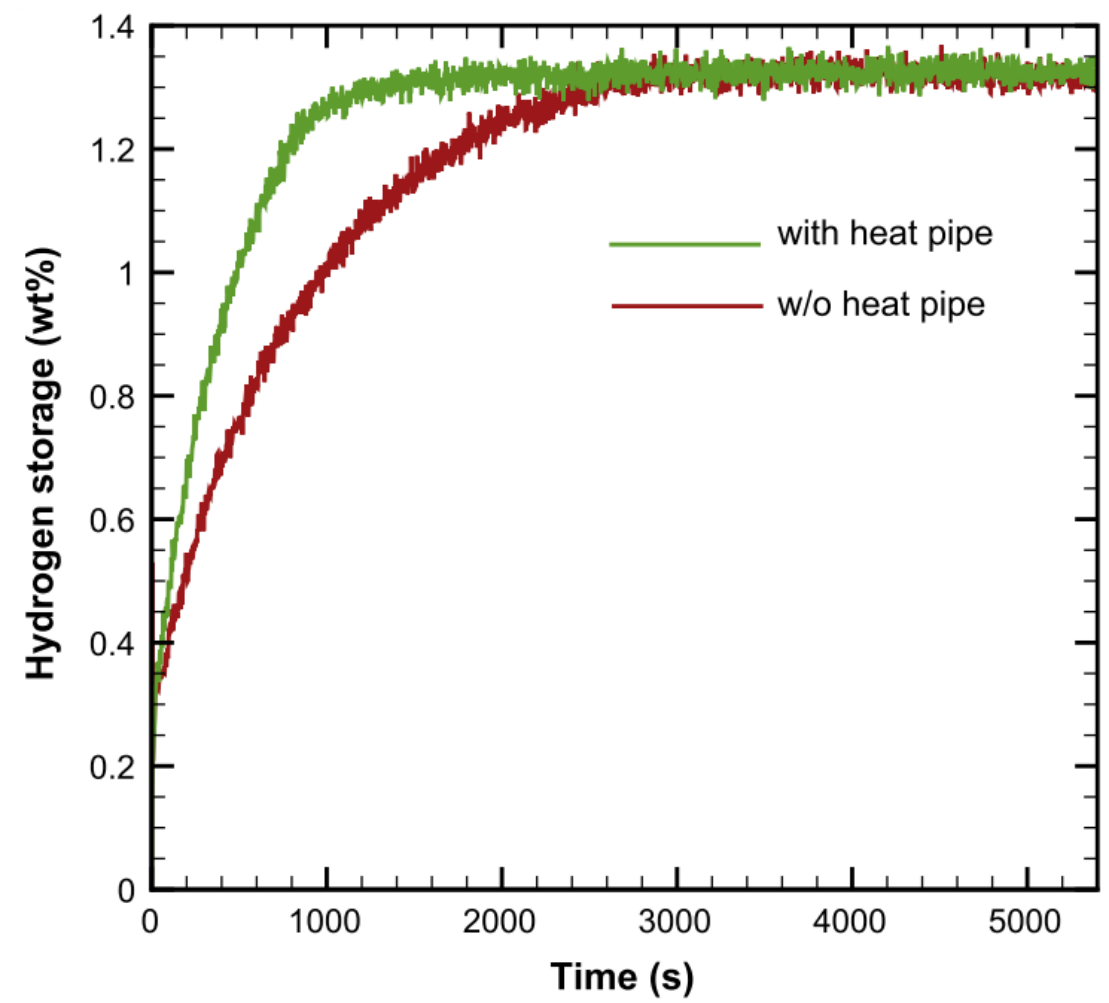

Figure 6 - Weight percent of hydrogen absorbed vs. charging time by experiment reproduced with permission from Elsevier [24]

The hydrogen absorption curves with and without the heat pipe from our baseline simulation are compared with the experimental results of Chung et al. [24] in Figure 6 . The experimental results show that to reach $95 \%$ saturation, the tank with the heat pipe needs $900 \mathrm{~s}$, whereas the one without the heat pipe needs $2100 \mathrm{~s}$. Our corresponding simulation results for these two cases are 1000 and $1952 \mathrm{~s}$, respectively. These results are thus within $10 \%$ of the experimental results, validating our numerical model with $\mathrm{LaNi}_{5}$ kinetics. Hence, our model can now be used to conduct parametric studies to quantify the influence of each parameter. 


\subsection{Summary}

In this chapter, we established a mathematical model for the metal hydridebased hydrogen storage tank incorporating a heat pipe. The assumptions of the model as well as the governing equations, boundary and initial conditions are described in detail. The numerical predictions of this model were validated against the experimental results of Chung et al. [24]. The hydrogen saturation time with and without the heat pipe agreed very well with experiments. Hence, we conclude that the boundary conditions, such as convective heat transfer coefficient have been correctly selected for the simulation and could be used with confidence in the following parametric studies. 


\section{Chapter 3}

\section{PARAMETRIC STUDY OF HYDROGEN STORAGE TANK}

\subsection{Overview}

Factors that will influence the hydrogen absorption rate include the heat pipe radius, their number and location, convective heat transfer coefficient of the heat pipe and the water jacket surrounding the tank, temperature of the water in the cooling jacket, thermal conductivity of the metal hydride, and the size of the tank. To systematically evaluate the effect of each of these parameters, a baseline value was specified for each, and only one parameter was varied at a time. This chapter presents results from a parametric study to determine the influence of these factors on filling time.

\subsection{Determination of Parameter Range}

In the previous chapter, we described our method to calculate the convective heat transfer coefficient of heat pipe, which is $1633.46 \mathrm{~W} / \mathrm{m}^{2} \mathrm{~K}$. We set $h=1600$ $\mathrm{W} / \mathrm{m}^{2} \mathrm{~K}$ as the heat transfer coefficient of the heat pipe for the baseline case. To investigate the influence of $h$ of the heat pipe on the rate of hydrogen storage, it was varied from 600 to $2000 \mathrm{~W} / \mathrm{m}^{2} \mathrm{~K}$.

The temperature and the convective heat transfer coefficient of the water jacket

for the base case were specified as $295 \mathrm{~K}$ and $60 \mathrm{~W} / \mathrm{m}^{2} \mathrm{~K}$, respectively, based on Chung et al. [24]. The convective coefficient was varied from 20 to $100 \mathrm{~W} / \mathrm{m}^{2} \mathrm{~K}$, and 
the water jacket temperature from 275 to $320 \mathrm{~K}$, to quantify their influence on the rate of hydrogen storage.

Another material parameter considered in the study is the thermal conductivity of $\mathrm{LaNi}_{5}$, which is very low. The thermal conductivity can be enhanced by adding Al foam to the tank, which also changes other material properties such as porosity and specific heat; all of these effective properties become functions of the Al foam percentage which we computed by the numerical method of [16]. For this parametric study, Al foam volume contents of $0,5,10$, and 20\% were considered; the baseline case did not include $\mathrm{Al}$ foam.

Finally, we investigated the effect of heat pipe radius and the incorporation of multiple heat pipes and their geometric arrangement for the case of a large tank with $100 \mathrm{~mm}$ radius. Heat pipes of 3, 5, 7, and $10 \mathrm{~mm}$ radius were studied with the smallest one chosen for the baseline study. For the larger tank, one to four heat pipes were introduced with different arrangements and the influence of the arrangement on the rate of hydrogen storage was investigated.

The baseline value for each parameter is listed in Table 2.

Table 2 - Baseline values for parameters and the ranges considered

\begin{tabular}{|c|c|c|}
\hline Parameter & $\begin{array}{c}\text { Baseline } \\
\text { value }\end{array}$ & Range \\
\hline Heat pipe radius $(\mathrm{mm})$ & 3 & $3-10$ \\
\hline Heat transfer coefficient of heat pipe $\left(\mathrm{W} / \mathrm{m}^{2} \mathrm{~K}\right)$ & 1600 & $600-2000$ \\
\hline Heat transfer coefficient of water jacket $\left(\mathrm{W} / \mathrm{m}^{2} \mathrm{~K}\right)$ & 60 & $20-100$ \\
\hline Temperature of water jacket $(\mathrm{K})$ & 295 & $275-320$ \\
\hline Aluminum foam content $(\%)$ & 0 & $0-40$ \\
\hline
\end{tabular}




\subsection{Effect of Convective Heat Transfer Coefficient of Heat Pipe}

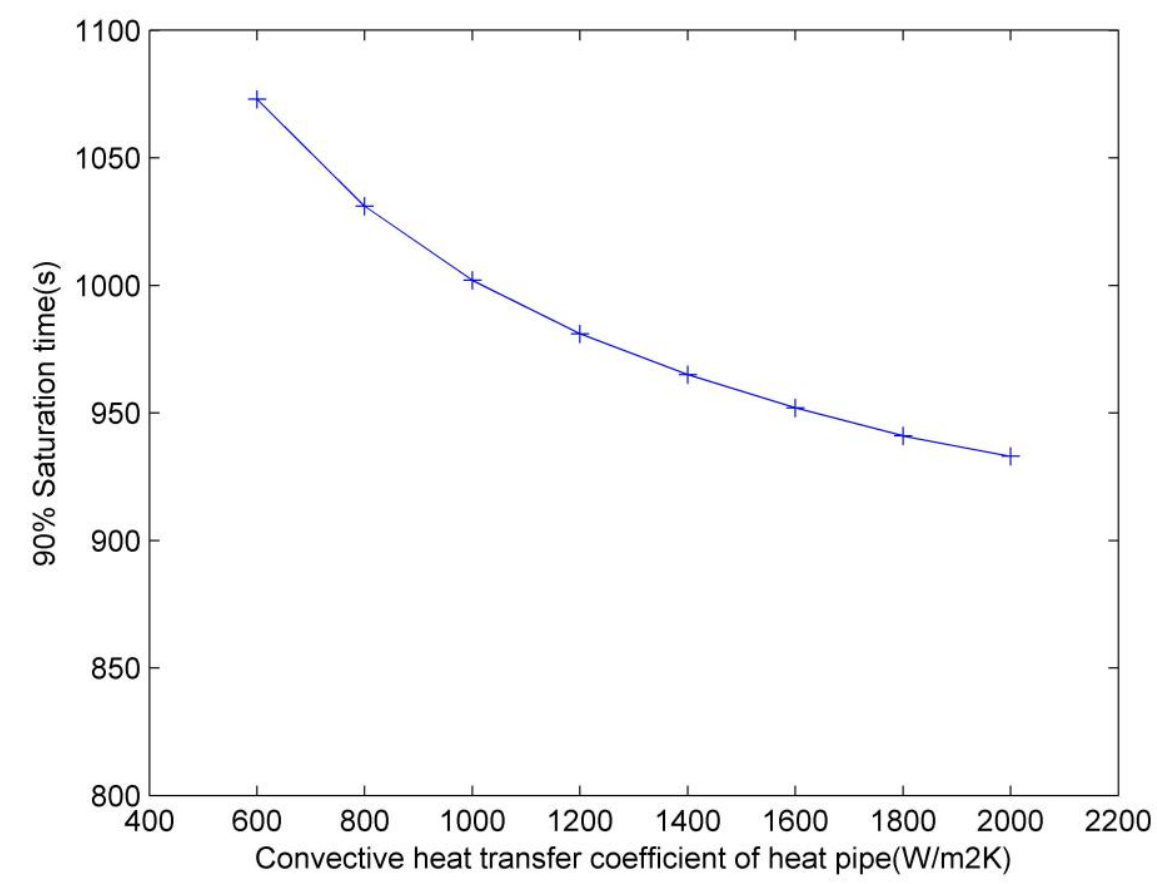

Figure 7 - Charging time for $90 \%$ hydrogen saturation of the tank as a function of convective heat transfer coefficient of the heat pipe

Figure 7 shows the $90 \%$ saturation time when all parameters were held to their baseline values in Table 2 and only the convective heat transfer coefficient of the heat pipe was varied from 600 to $2000 \mathrm{~W} / \mathrm{m}^{2} \mathrm{~K}$ in increments of $200 \mathrm{~W} / \mathrm{m}^{2} \mathrm{~K}$. The results show that the $90 \%$ saturation time decreased from $1073 \mathrm{~s}$ to $933 \mathrm{~s}$, thus the charging time was reduced by $13 \%$. It is also seen that increasing the heat transfer coefficient provides diminishing gains. For example, doubling $h$ from 600 to $1200 \mathrm{~W} / \mathrm{m}^{2} \mathrm{~K}$ reduced the saturation time by $8.6 \%$, whereas when $h$ was doubled from 1000 to 2000 $\mathrm{W} / \mathrm{m}^{2} \mathrm{~K}$, the time reduced by only $6.9 \%$. Thus, while a heat pipe with more efficient 
heat transfer is desirable, its ability to reduce saturation time diminishes with increasing $h$.

\subsection{Effect of Convective Heat Transfer Coefficient of the Water Jacket}

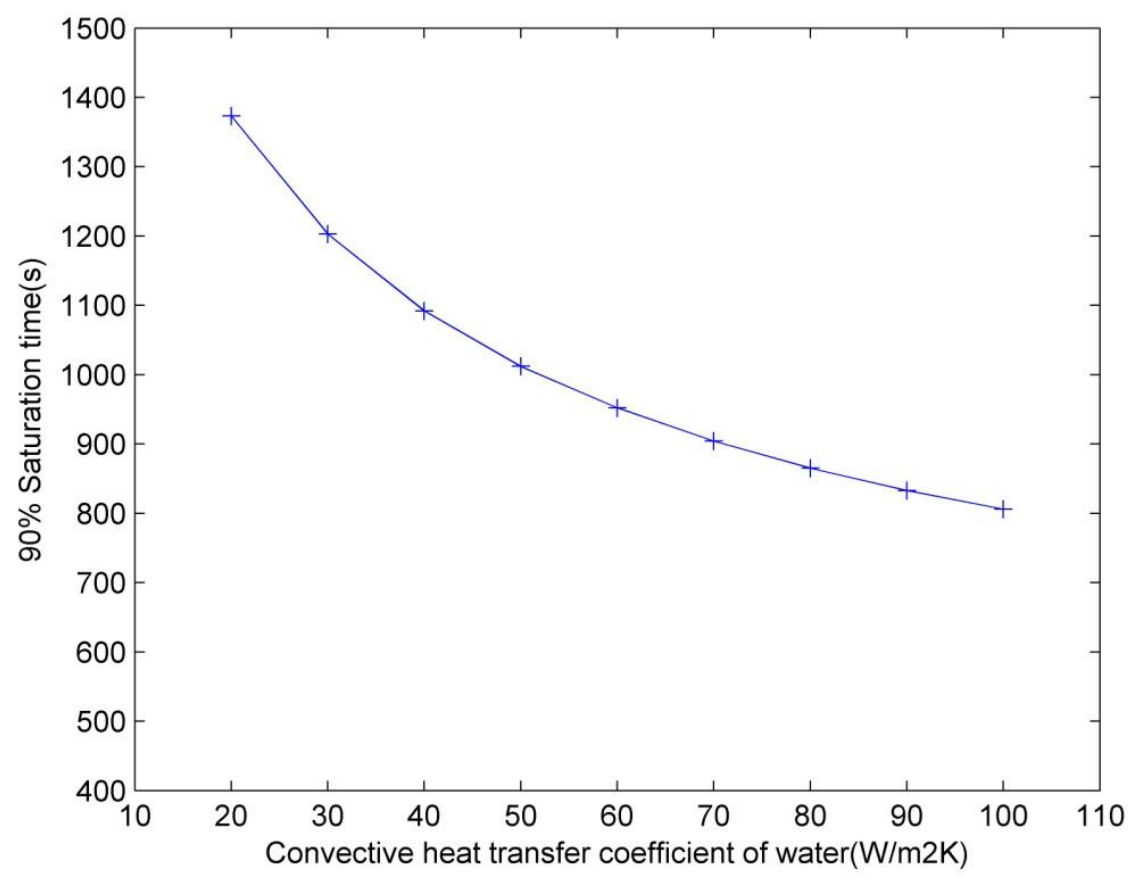

Figure 8 - Charging time for $90 \%$ hydrogen saturation of the tank as a function of convective heat transfer coefficient of the water jacket

The $90 \%$ saturation time with the baseline parameters listed in Table 2 with varying convective heat transfer coefficient of the water jacket $\left(h_{w}\right)$ is shown in Figure 8, where $h_{w}$ was increased from 20 to $100 \mathrm{~W} / \mathrm{m}^{2} \mathrm{~K}$ in increments of $10 \mathrm{~W} / \mathrm{m}^{2} \mathrm{~K}$. The total improvement in saturation time is about $50 \%$ as one goes from 20 to 100 $\mathrm{W} / \mathrm{m}^{2} \mathrm{~K}$. Again, the improvement is non-linear and tails off at higher values of $h_{w}$. 


\subsection{Effect of Water Jacket Temperature}

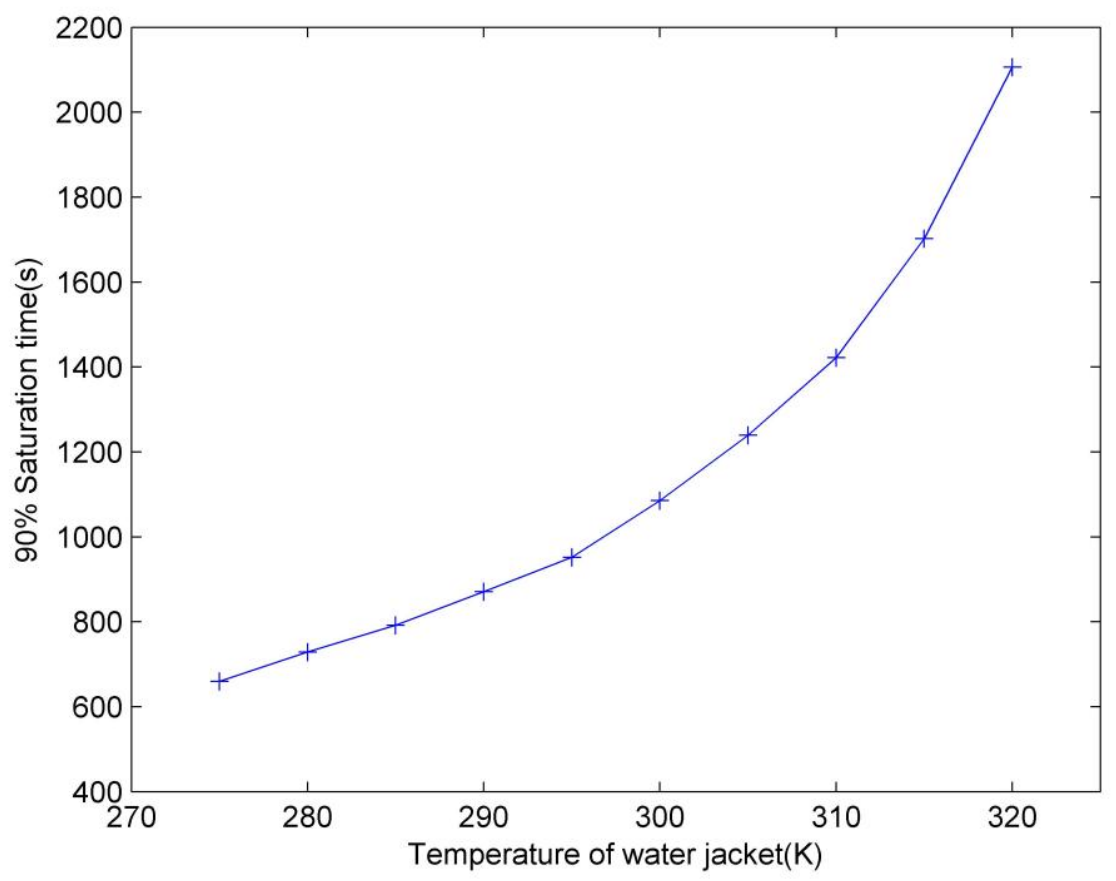

Figure 9 - Charging time for $90 \%$ hydrogen saturation of the tank as a function of the water jacket temperature

The influence of the water jacket temperature that surrounds the hydride tank on filling time was investigated by varying the water jacket temperature from 275 to $320 \mathrm{~K}$ in increments of $5 \mathrm{~K}$. All other parameters were held at their baseline value as listed in Table 2 . Figure 9 shows that the $90 \%$ saturation time is very sensitive to the water jacket temperature. Higher temperatures increase the saturation time dramatically because the heat removal rate decreases as the water jacket temperature is increased, which slows down the rate of hydrogen absorption. 


\subsection{Effect of Al Foam}

Addition of $\mathrm{Al}$ foam into the metal hydride tank increases the medium's effective thermal conductivity allowing it to conduct the heat of reaction out of the system quickly. In the simulation, the numerical method of [16] was used to calculate the effective thermal conductivity of the metal hydride/Al foam mixture, and the rule of mixtures was used to calculate the density and heat capacity. Table 3 lists these property values for Aluminum and $\mathrm{LaNi}_{5}$, which are the two materials comprising the mixture. The values of the effective thermal conductivity, density, and heat capacity for different percentages of $\mathrm{Al}$ foam are shown in Figure 10.

Table 3 - Property values for Aluminum and $\mathrm{LaNi}_{5}$

\begin{tabular}{|c|c|c|c|}
\hline & $\begin{array}{c}\text { Thermal Conductivity } \\
(\mathbf{W} / \mathbf{m}-\mathbf{k})\end{array}$ & $\begin{array}{c}\text { Heat Capacity } \\
(\mathbf{J} / \mathbf{k g}-\mathbf{K})\end{array}$ & $\begin{array}{c}\text { Density } \\
\left(\mathbf{k g} / \mathbf{m}^{\mathbf{3}}\right)\end{array}$ \\
\hline Aluminum & 202.4 & 871 & 2719 \\
\hline $\mathrm{LaNi}_{5}$ & 2.4 & 419 & 8400 \\
\hline
\end{tabular}




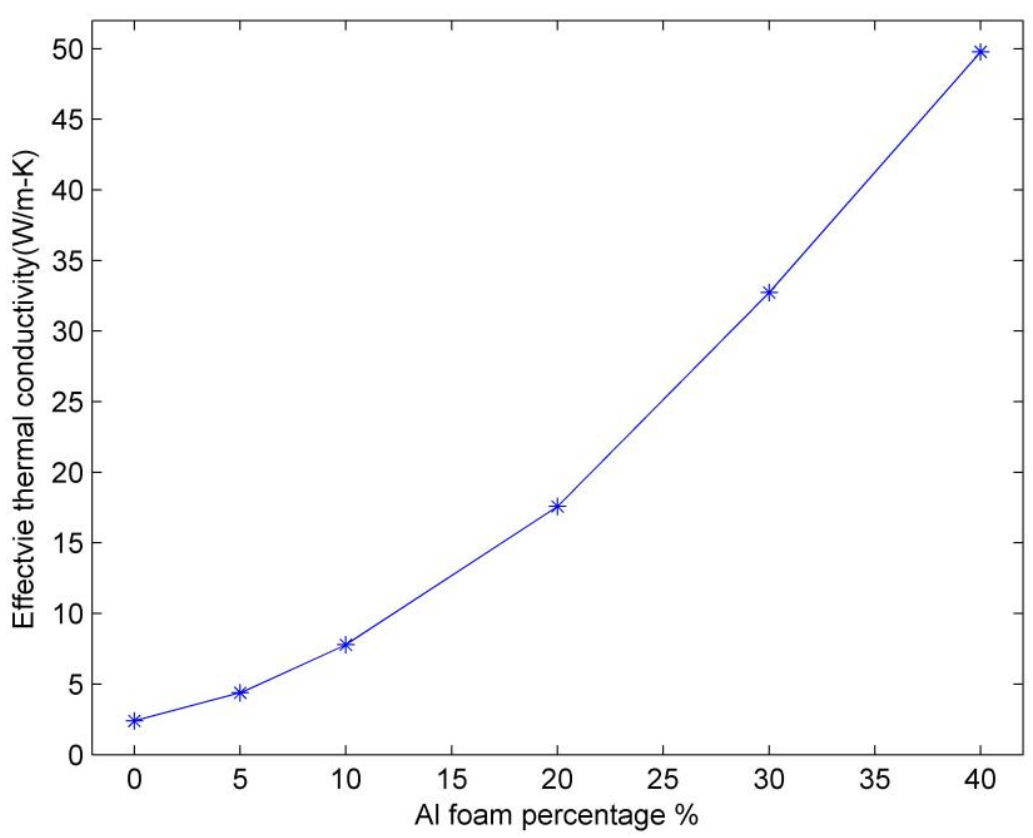

a.

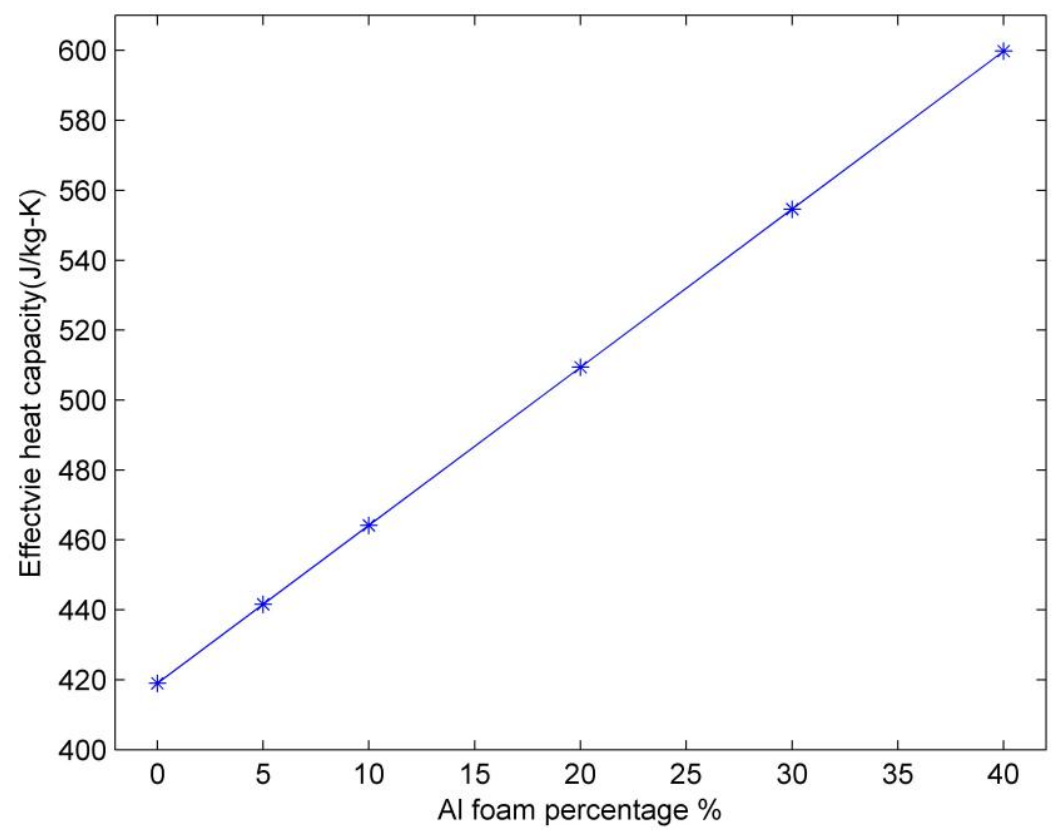

b. 


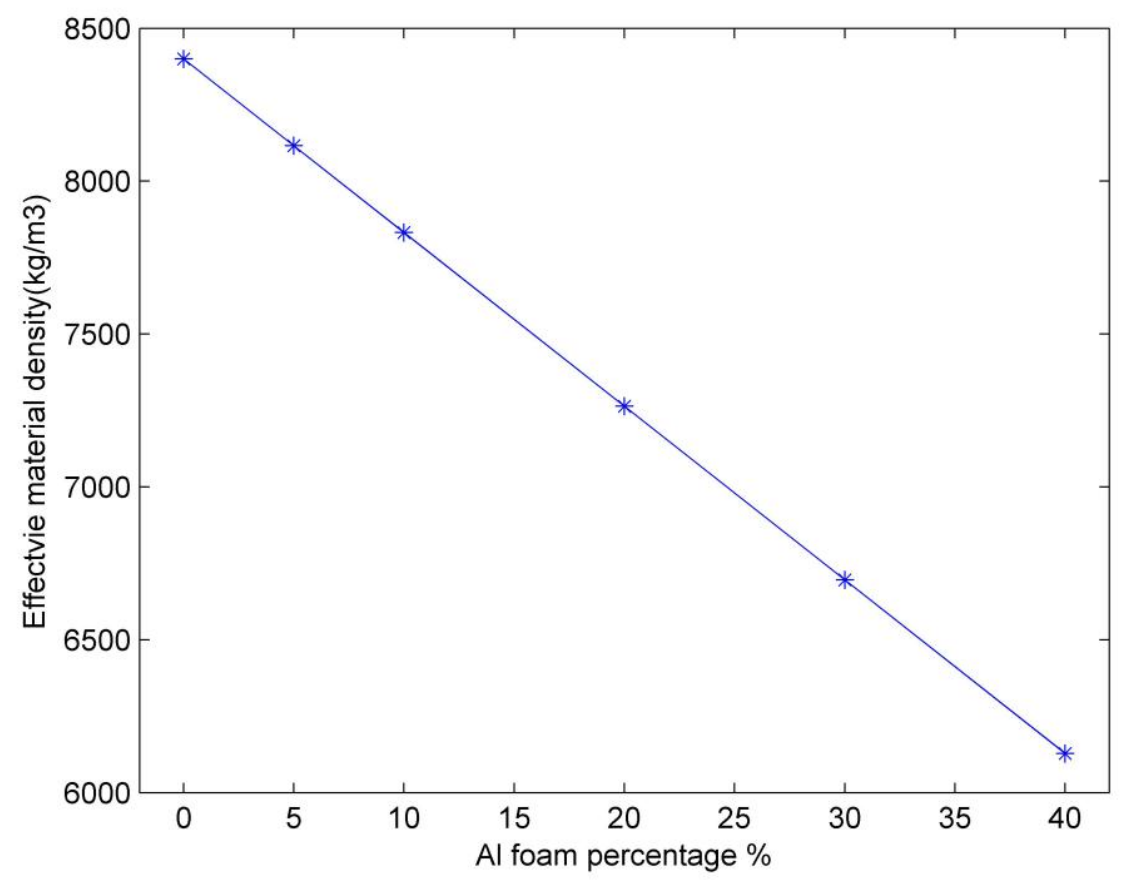

c.

Figure 10 - Effective property values of metal hydride/Al foam mixture: (a) thermal conductivity; (b) heat capacity; (c) material density.

The parametric study was conducted for additions of 5, 10 and 20\% Al foam to the hydride. For each combination, the effect of the convective heat transfer coefficient of the heat pipe and water jacket was also explored. As expected, the results in Figures 11 and 12 show that as $\mathrm{Al}$ foam content is increased, the saturation time decreases. However, the trend of the saturation time with varying $h$ is the same for all $\mathrm{Al}$ foam contents as indicated by the four plots in Figures 11 and 12 being nearly parallel, which suggests that the heat removal limiting step is the thermal conductivity of the medium and not the $h$ value of the water jacket or the heat pipe. 


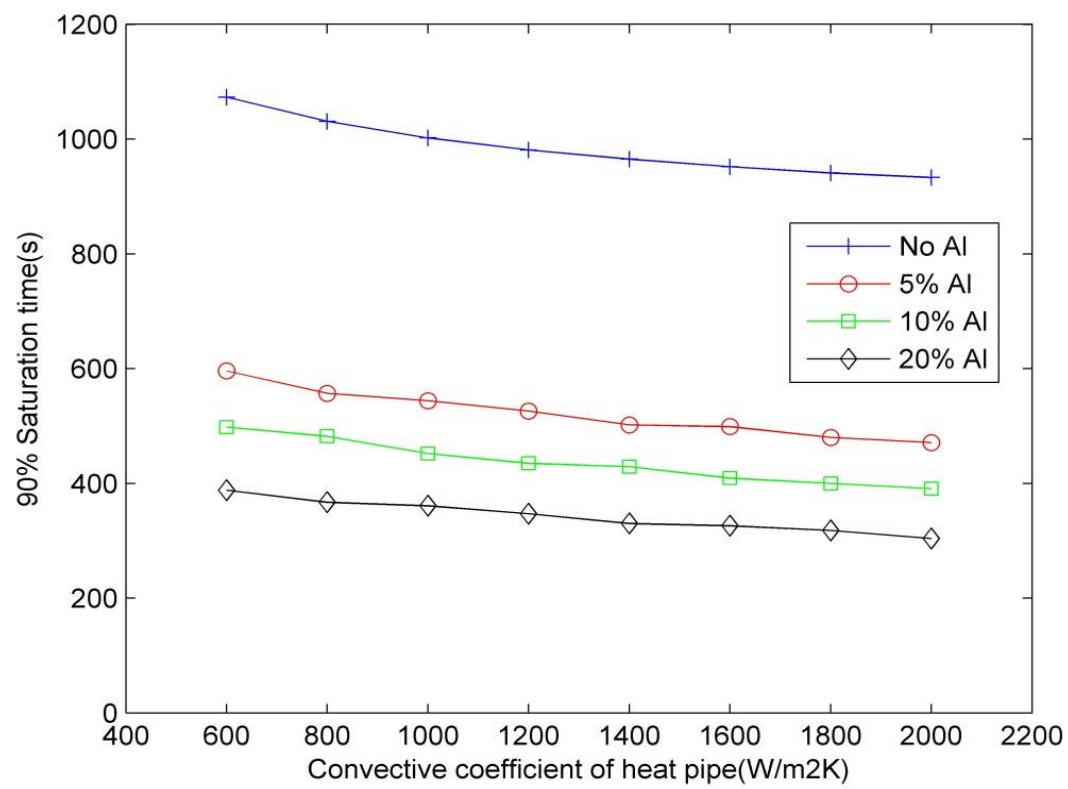

Figure 11 - Effect of Al foam content on saturation time for varying convective heat transfer coefficient of the heat pipe

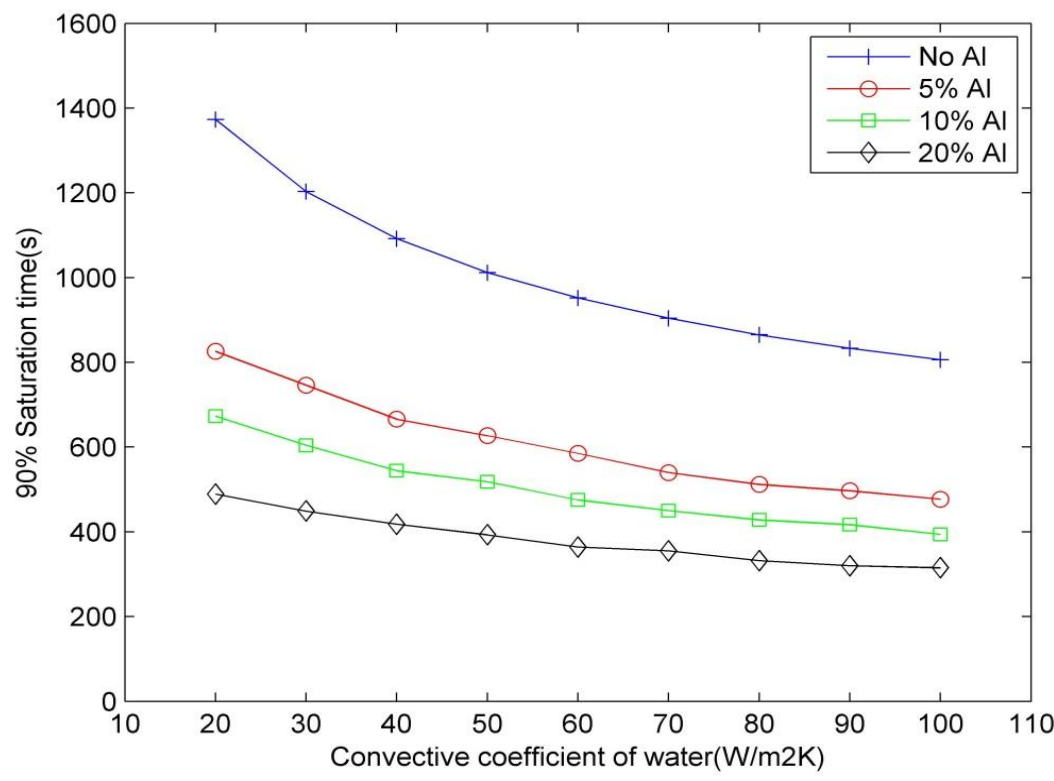

Figure 12 - Effect of Al foam content on saturation time for varying convective heat transfer coefficient of the cooling water jacket 


\subsection{Summary}

In this chapter, we conducted a parametric study of a metal hydride-based hydrogen storage tank incorporating a heat pipe by varying the convective heat transfer coefficient of the heat pipe and the water jacket, the temperature of the water jacket, and the Al foam content. We provided details on how we determined the range for each parameter and then simulated each case using Ansys Fluent.

The results showed that increasing the heat convection coefficient reduces the hydrogen charging time although the rate of improvement diminishes with increasing $h$. It was also found that water jacket temperatures higher than $300 \mathrm{~K}$ greatly reduce the heat removal rate. The addition of $\mathrm{Al}$ foam was found to reduce the total reaction time, thus it is better to combine the heat pipe with Al foam in the hydrogen storage tank. 


\section{Chapter 4}

\section{OPTIMIZATION STUDY FOR HEAT PIPE PLACEMENT IN LARGE TANK}

\subsection{Overview}

A scaled-up hydrogen storage tank is required to meet the DOE automotive target for onboard hydrogen storage. Our goal in this chapter is to study the effectiveness of heat pipes in reducing the filling time for large hydride-based hydrogen storage tanks suitable for automotive applications.

In this chapter, we first show that a single, centrally-located heat pipe is insufficient to reduce the filling time to a reasonable value. Next, we study the effect of heat pipe radius on the size of the $90 \%$ saturation area surrounding that heat pipe in order to gain insights into how to arrange multiple heat pipes in a larger tank. Then we study the hydrogen filling time for various arrangements of up to four heat pipes. Since the poor heat conductivity of $\mathrm{LaNi}_{5}$ also limits the heat removal rate in a large tank, we studied the effect of Al foam content for these cases.

The heat pipe radius influences the heat removal rate because the surface area of the heat pipe scales linearly with its radius. Therefore, we also studied the effect of heat pipe radius in this chapter. The baseline value of the heat pipe radius is set to 3

$\mathrm{mm}$ to match the radius used by Chung et al. [24] in their experiment, and we conducted a parametric study for radii ranging from 3 to $10 \mathrm{~mm}$. Increasing the heat pipe radius causes a displacement of active hydride material from the tank, hence we selected an upper bound of $10 \mathrm{~mm}$ in our study. 


\subsection{Effect of Scaling Up the Storage Tank}

For realistic automotive applications, the metal hydride tank needs to store a few kilograms of hydrogen. Hence, if we scale up the dimensions of the baseline tank geometry by a factor of 10 , it can accommodate $280 \mathrm{~kg}$ of $\mathrm{LaNi}_{5}$ at a fill factor of $60 \%$. For a gravimetric hydrogen storage density of $1.5 \mathrm{wt} \%$, this tank would be able to store approximately $4 \mathrm{~kg}$ of hydrogen.

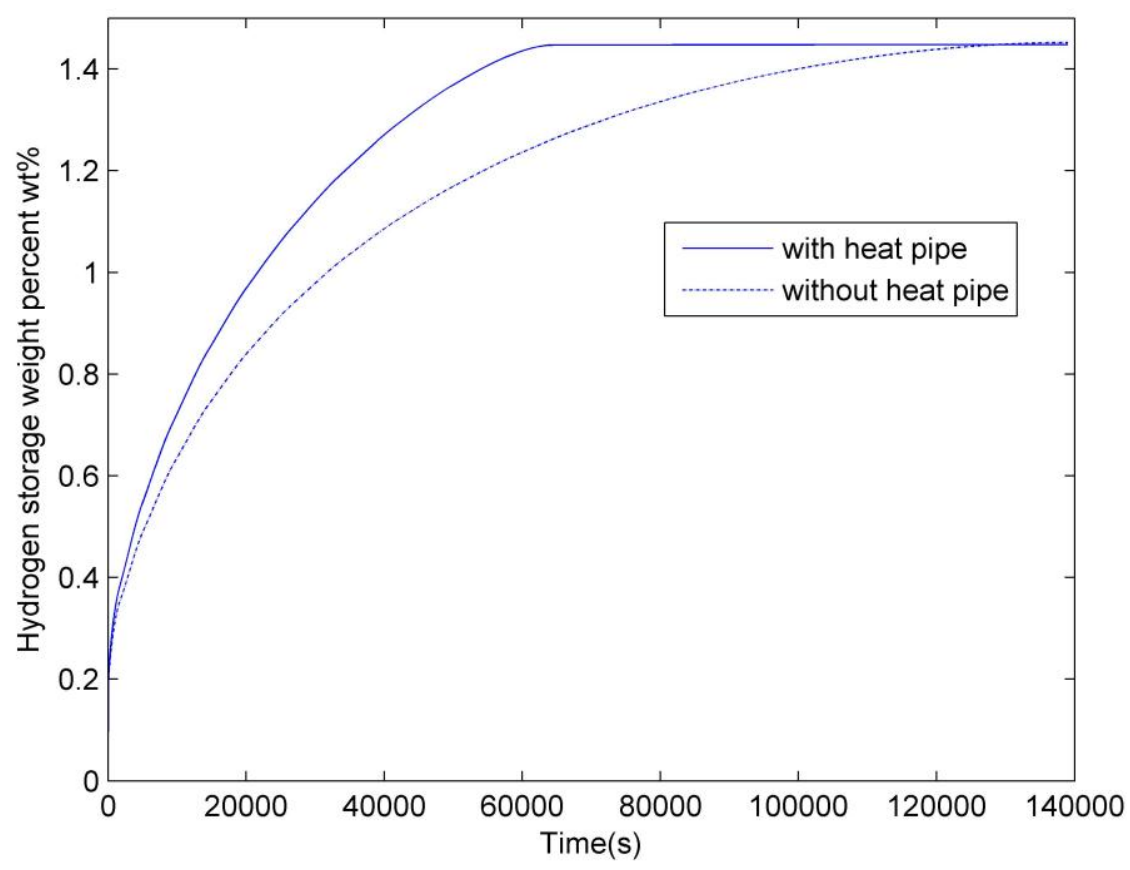

Figure 13 - Weight percent of hydrogen absorbed vs. charging time in a large tank containing $280 \mathrm{~kg}$ of metal hydride

Figure 13 shows the simulation results for the scaled-up tank with and without the heat pipe using baseline values for all other parameters. The tank without the heat pipe takes about 26 hours to reach $95 \%$ of full capacity, whereas the introduction of 
just one heat pipe reduces this time to about 14 hours. It is clear from this simulation that to reduce the charging time to a few minutes, multiple heat pipes will be required. However, when incorporating multiple heat pipes, their relative location becomes important. For example, if the pipes are too close to each other, only the proximal regions will saturate quickly while distal regions will saturate slowly, increasing the saturation time. The next section explores the hydrogen saturation dynamics in the neighborhood of the heat pipe as a function of the heat pipe radius.

\subsection{Saturation Radius}

The simulation result with the large tank showed that it took an extremely long time to saturate when incorporating only one heat pipe. One way to reduce filling time further is to incorporate more heat pipes within the tank. However, with multiple heat pipes, their relative position becomes important. If the heat pipes are placed too closely together, their saturation areas would overlap and the full potential of each heat pipe to remove heat would not be realized. On the other hand, if they are spaced too far apart, the total saturation time would still be very high.

One approach for solving this problem is to determine the $90 \%$ saturation radius for a single heat pipe in a given time. Since our goal is to complete the filling process in $3 \mathrm{~min}$, we will examine the $90 \%$ saturation radius for a single heat pipe after 3 min of charging. Then, to prevent interference with other heat pipes, we only have to ensure that they are separated by twice the $90 \%$ saturation radius. Knowing the $90 \%$ saturation radius of one heat pipe in a given time, it is straightforward to calculate the total number of heat pipes required to saturate the entire tank in that same time period. 
To investigate how quickly the region around the heat pipe reaches $90 \%$ saturation, a two-dimensional model of a $200 \mathrm{~mm} \times 200 \mathrm{~mm}$ square tank with a heat pipe at its center was created as shown in Figure 14. The hydrogen inlet is at the center of the top edge, and the inlet pressure is 10 bar. The heat pipe at the center is assigned the baseline value of the convective heat transfer coefficient of $1600 \mathrm{~W} / \mathrm{m}^{2} \mathrm{~K}$. Unlike the earlier parametric studies, the outer boundary of the square tank is insulated, as we want the heat pipe to be the only avenue for heat removal. We also conducted simulations with $5,10,20,30$ and $40 \%$ Al foam to improve heat conduction and recorded the $90 \%$ saturation radius as a function of time. The $90 \%$ saturation radius is defined as the radial distance from the circumference of the heat pipe to the edge of the region that is $90 \%$ saturated with hydrogen. We also investigated the effect of heat pipe radius $(3,5,7$ and $10 \mathrm{~mm})$ on the saturation radius.

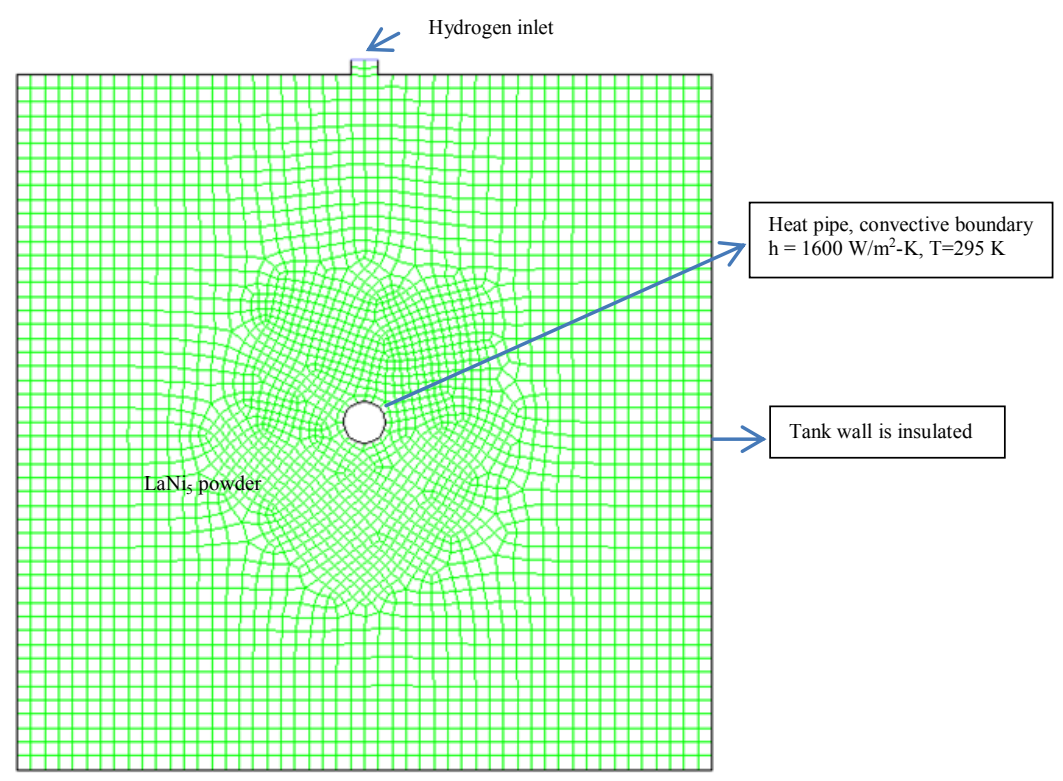

Figure 14 - Computational mesh for storage tank to study hydrogen saturation dynamics in the neighborhood of the heat pipe 
The results are shown in Figure 15. The $y$-axis represents the $90 \%$ saturation radius (i.e. the size of the region around the heat pipe that is $90 \%$ saturated with hydrogen), and the $x$-axis represents the $\mathrm{Al}$ foam $\%$ in the hydride bed. Plots are shown for different time intervals ranging from 4 to $15 \mathrm{~min}$, and for four heat pipe radii. An interesting result was observed while recording the $90 \%$ saturation radius at early times. For example, at $7 \mathrm{~min}$ with the $3 \mathrm{~mm}$ heat pipe, $5 \mathrm{~min}$ with the $5 \mathrm{~mm}$ heat pipe, and $4 \mathrm{~min}$ with the $7 \mathrm{~mm}$ heat pipe, the saturation radius surprisingly dropped as the $\mathrm{Al}$ foam content was increased beyond $10 \%$. This is because a higher Al foam content further increases the heat conductivity of the Al hydride mixture, which expands the region around the heat pipe that can absorb hydrogen. In these cases, the reaction occurs not only in the immediate vicinity of the heat pipe but over a larger area, hence more material reacts and more heat is generated. The heat pipe can remove heat only at a prescribed rate, and therefore, it takes longer for this larger area to reach $90 \%$ saturation. 


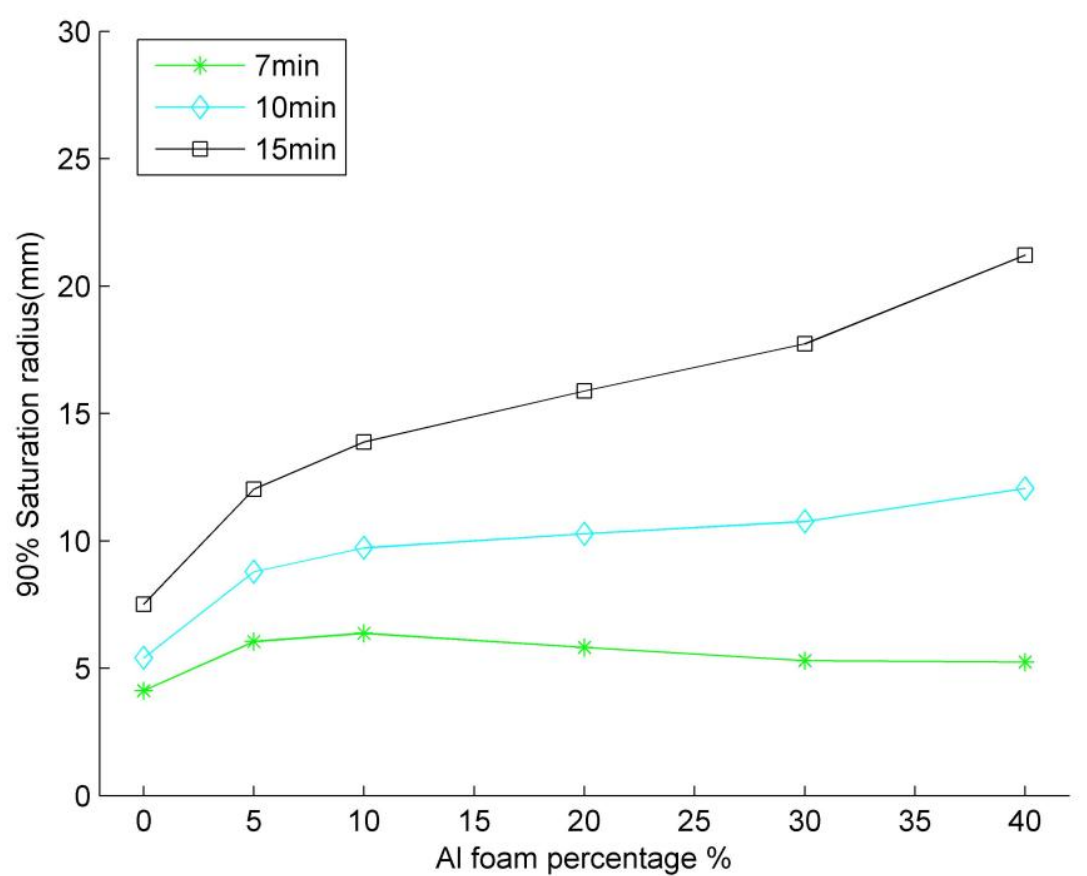

a.

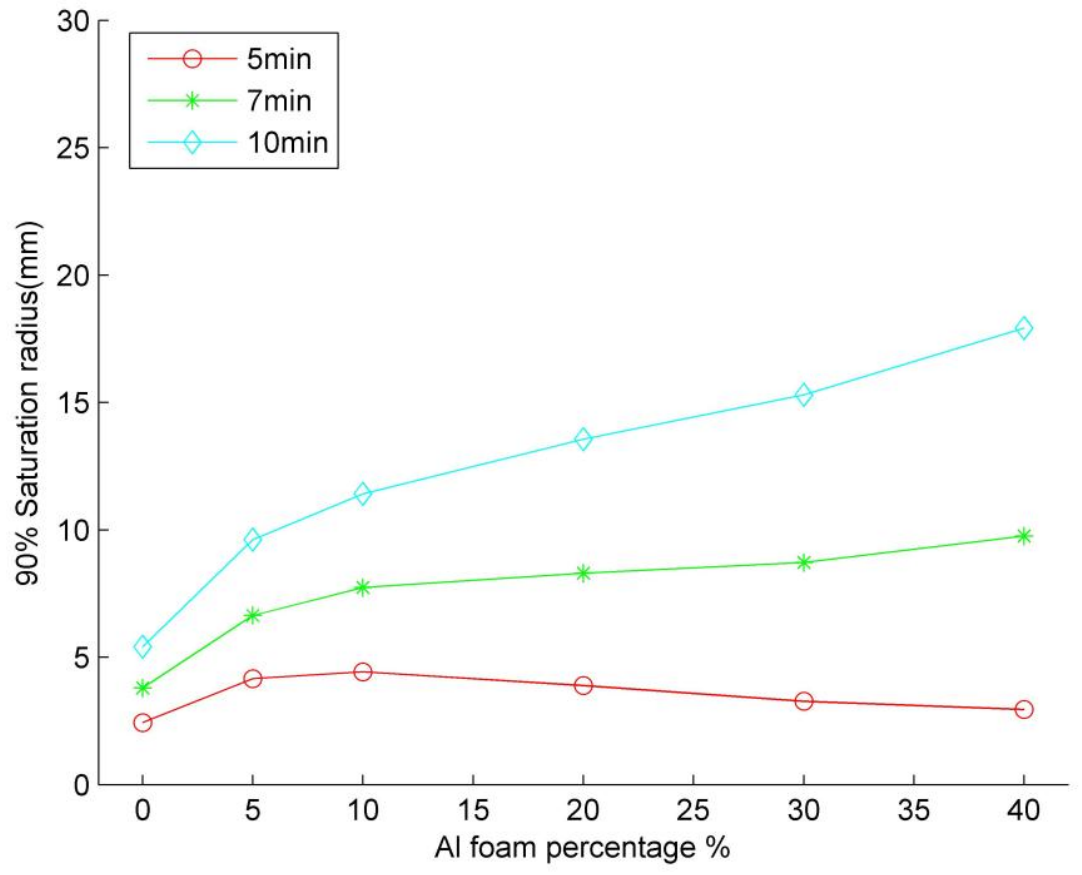

b. 


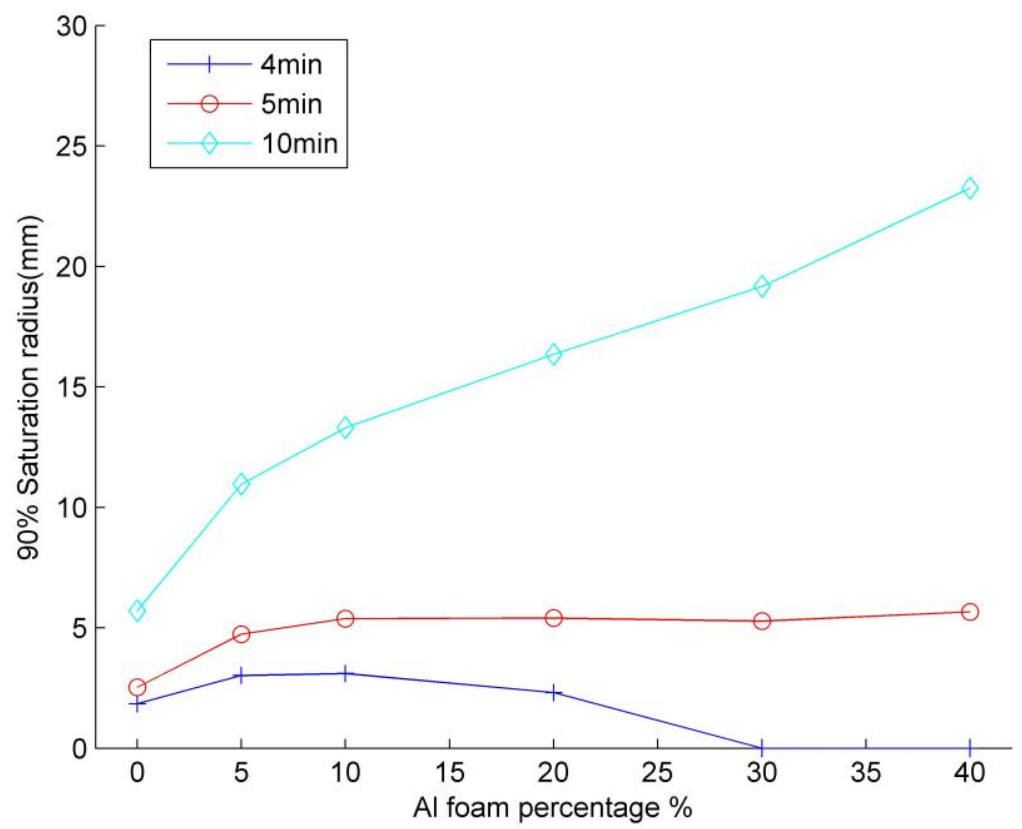

c.

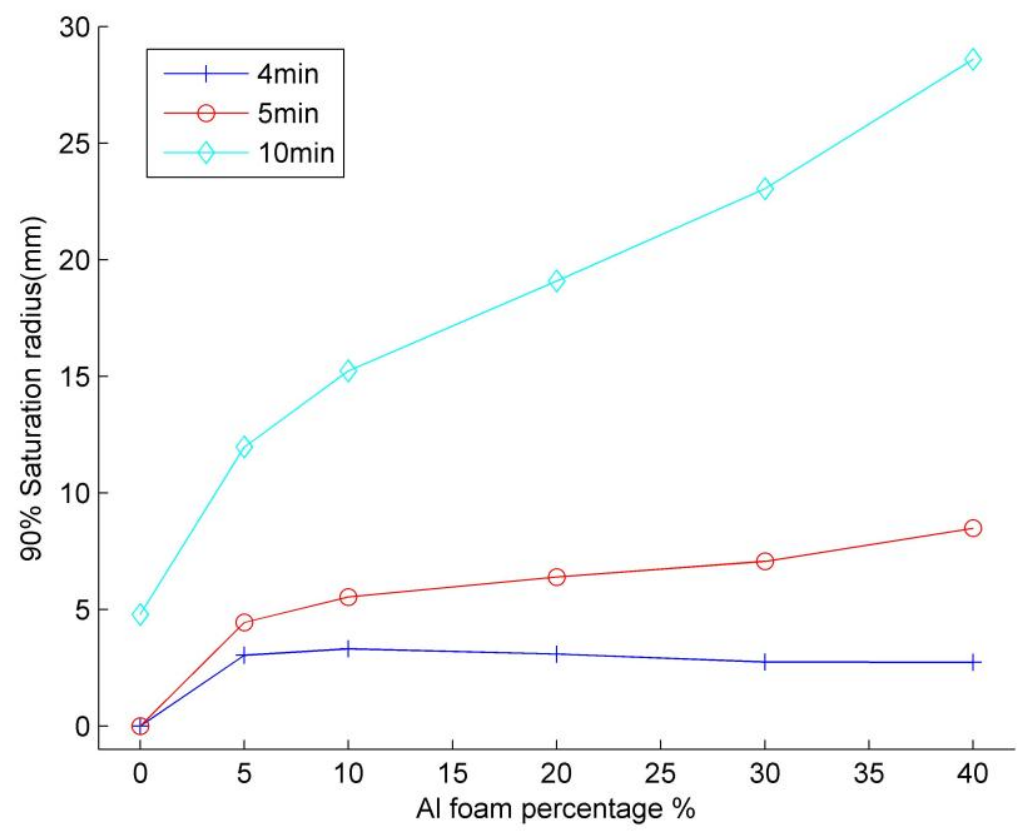

Figure 15 - Saturation radius (radius of the region with $90 \%$ saturation) for varying $\mathrm{Al}$ foam content ( 0 to $40 \%$ ) at various time intervals for different heat pipe radii. (a) $3 \mathrm{~mm}$, (b) $5 \mathrm{~mm}$, (c) $7 \mathrm{~mm}$, (d) $10 \mathrm{~mm}$ 
Figure 16 shows contour plots for hydrogen saturation after $7 \mathrm{~min}$ for the 3 $\mathrm{mm}$ heat pipe for varying Al foam content. Similar results were obtained for other heat pipe radii. As expected, the saturation zone is circular, and its area increases with increasing $\mathrm{Al}$ foam content. More hydride material reacts for higher Al foam content, and hence more heat is generated. Therefore, for the same heat convection coefficient of the heat pipe, it takes longer for this larger area to reach $90 \%$ saturation.

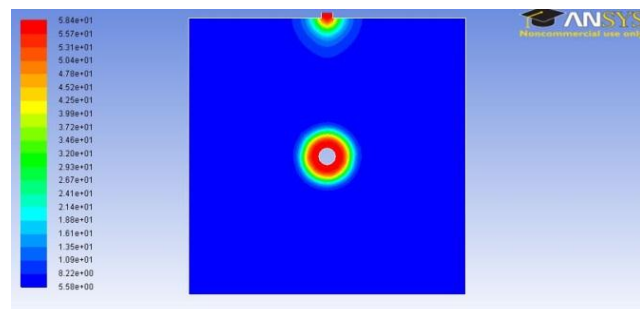

a.

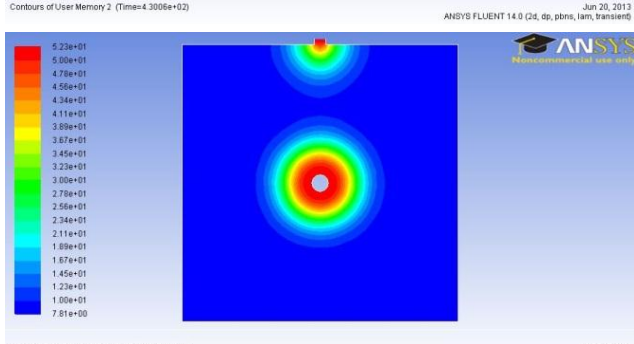

c.

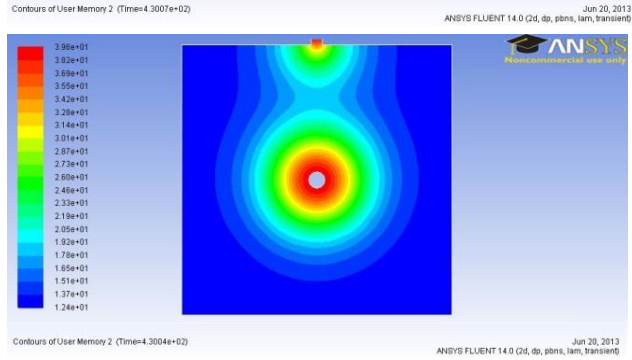

e.

b.
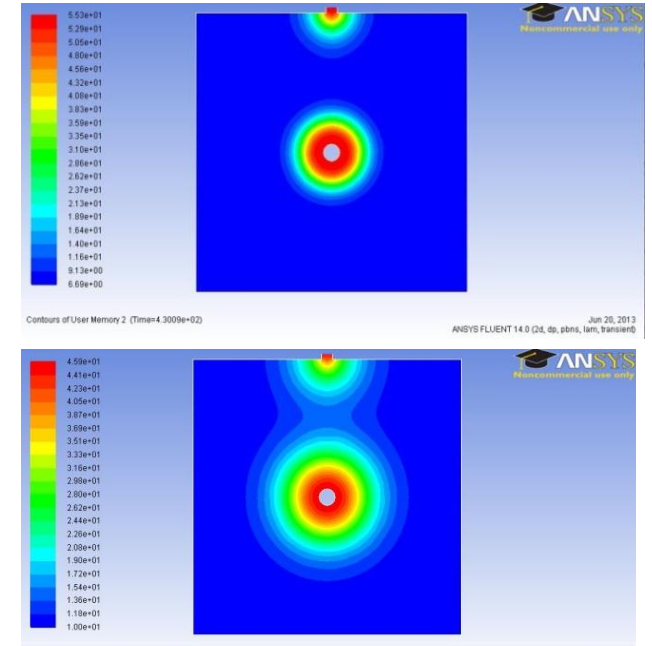

d.

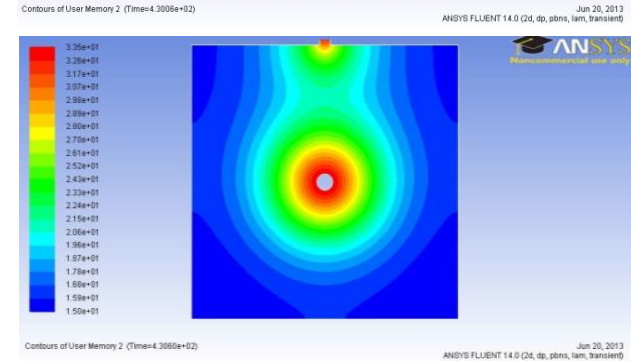

Figure 16 - Contour plots of saturation at $7 \mathrm{~min}$ for a $3 \mathrm{~mm}$ heat pipe with varying amounts of $\mathrm{Al}$ foam: (a) $0 \%$; (b) $5 \%$; (c) $10 \%$; (d) $20 \%$; (e) $30 \%$; and (f) $40 \%$. 
Figure 17 shows the radial distribution of the saturation percentage from the circumference of the heat pipe towards the tank wall boundary. The result is plotted at the end of $7 \mathrm{~min}$ after the introduction of hydrogen for a heat pipe of $3 \mathrm{~mm}$ radius for varying $\mathrm{Al}$ foam content. It is immediately obvious that for $0 \% \mathrm{Al}$, the saturation level drops steeply away from the heat pipe. On the other hand, the curve for $40 \% \mathrm{Al}$ foam is much flatter showing that regions far away from the heat pipe have much high saturation levels than for no aluminum. As expected, the area under the curve for $40 \%$ $\mathrm{Al}$ is much larger showing more saturation overall, but when we focus on the region whose saturation exceeds $90 \%$, it is actually smaller. One can understand this easily by conducting a thought experiment in which the hydride bed has infinite thermal conductivity. In this situation, the entire tank will absorb hydrogen at exactly the same rate and the hydrogen saturation level will be uniform with radius, but it will take longer to reach $90 \%$ saturation because the heat removal rate is limited. However, when the $\mathrm{Al}$ foam is increased, although the saturation rate improves, less hydrogen can be stored in the tank because the Al foam displaces the active hydride material. Hence, the optimal Al foam content depends on the tank size and the number of heat pipes, and the time in which one wishes to fill $90 \%$ hydrogen in the tank. 


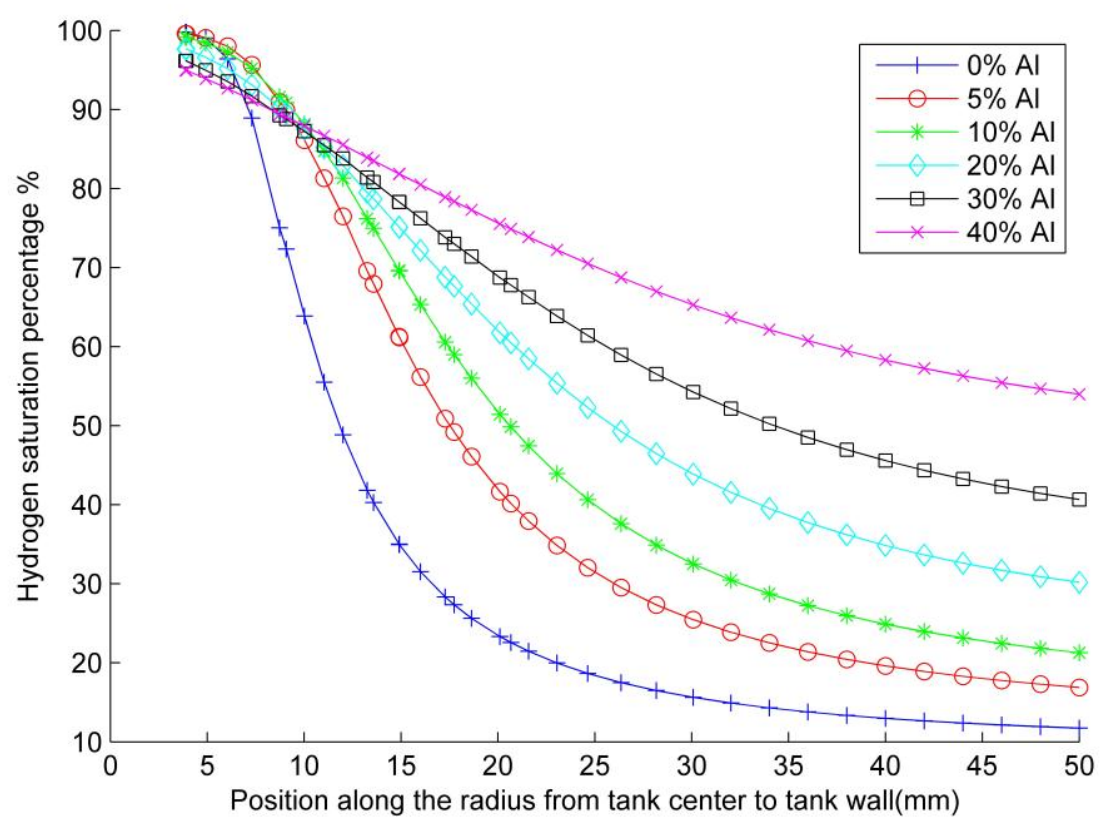

Figure 17 - Hydrogen saturation as a function of tank radius for a $3 \mathrm{~mm}$ heat pipe at 7 minutes, with $\mathrm{Al}$ foam content ranging from 0 to $40 \%$

Knowing the $90 \%$ saturation radius for heat pipes with different radii, it is easy to calculate the number of heat pipes required for a hydrogen storage tank of given size to reach $90 \%$ saturation. For example, let us consider a hydrogen storage tank with radius $100 \mathrm{~mm}$ and height $800 \mathrm{~mm}$, and a $90 \%$ saturation time of $10 \mathrm{~min}$. Table 4 lists the $90 \%$ saturation radius at time equal to 10 minutes for varying heat pipe size with 0,5 , and $10 \% \mathrm{Al}$ foam added.

Table 4 - Ten minutes saturation radius for varying heat pipe sizes

\begin{tabular}{|c|c|c|c|c|}
\hline Heat pipe radius (mm) & $\mathbf{3}$ & $\mathbf{5}$ & $\mathbf{7}$ & $\mathbf{1 0}$ \\
\hline 90\% Saturation radius without Al foam (mm) & 5.4 & 5.41 & 5.7 & 5.8 \\
\hline 90\% Saturation radius with 5\% Al foam (mm) & 8.78 & 9.62 & 10.96 & 11.96 \\
\hline 90\% Saturation radius with 10\% Al foam (mm) & 9.72 & 11.47 & 13.3 & 15.23 \\
\hline
\end{tabular}


For example, for the $10 \mathrm{~mm}$ heat pipe case with $5 \% \mathrm{Al}$ foam, each heat pipe would occupy an area of $\pi(10+11.96)^{2}=1514.24 \mathrm{~mm}^{2}$, and so the total number of required heat pipes would be $\frac{\pi 100^{2}}{1514.24} \approx 21$. With $10 \% \mathrm{Al}$ foam, the required number of heat pipes drops to 16 , while 40 heat pipes are needed in the complete absence of $\mathrm{Al}$ foam. When adding heat pipes and $\mathrm{Al}$ foam into the hydrogen storage tank, the gravimetric and volumetric densities should also be considered. The gravimetric and volumetric density can be calculated by the following equations:

Gravimetric density

$$
\begin{gathered}
\qquad=\frac{\operatorname{Mass}_{H 2}}{\text { Mass }_{\text {tank }}+\operatorname{Mass}_{\text {LaNi5 }}+\operatorname{Mass}_{H 2}+\operatorname{Mass}_{\text {HeatPipe }}+M_{a s S_{A l}}} \\
\text { Volumetric density }=\frac{\text { Masst }_{H 2}}{\text { Volume of the whole storage system }}
\end{gathered}
$$

Assume the thickness of the tank is $10 \mathrm{~mm}$ and made of steel, which has a density of $8050 \mathrm{~kg} / \mathrm{m}^{3}$. Then the volume of the tank equals $\pi\left(110^{2}-100^{2}\right) \times 800 \times 10^{-9}=$ $0.0053 \mathrm{~m}^{3}$, and hence the mass of the tank equals $8050 \times 0.0053=42.7 \mathrm{~kg}$. In addition, we assume heat pipe is made of copper with the density of $8960 \mathrm{~kg} / \mathrm{m}^{3}$, and the thickness of heat pipe is $1 \mathrm{~mm}$. With the same method, we computed the mass of one pipe is $\pi\left(10^{2}-9^{2}\right) \times 800 \times 10^{-9} \times 8960=0.42 \mathrm{~kg}$.

Table 5 shows the amount of hydrogen that can be stored in 10 minutes as well as the corresponding gravimetric and volumetric densities under these conditions. It is seen that the $5 \% \mathrm{Al}$ foam with 21 heat pipes case and the 10\% $\mathrm{Al}$ foam with 16 heat pipes case give very similar results, and both perform better than incorporating 40 heat pipes without Al foam. Similar calculations can be conducted for other heat pipe sizes using their saturation radii listed in Table 4. 
Table 5 - Number of heat pipes of $10 \mathrm{~mm}$ radius and mass of stored hydrogen in 10 minutes with different amounts of $\mathrm{Al}$ foam

\begin{tabular}{|c|c|c|c|c|}
\hline $\begin{array}{c}\text { Al } \\
\text { foam \% }\end{array}$ & $\begin{array}{c}\text { Number of heat } \\
\text { pipes }\end{array}$ & $\begin{array}{c}\text { Hydrogen } \\
\text { stored (kg) }\end{array}$ & $\begin{array}{c}\text { Gravimetric } \\
\text { density }\end{array}$ & $\begin{array}{c}\text { Volumetric } \\
\text { density }\left(\mathbf{k g} / \mathbf{m}^{\mathbf{3}}\right)\end{array}$ \\
\hline 0 & 40 & 0.88 & 0.0074 & 28.16 \\
\hline 5 & 21 & 0.93 & 0.0077 & 30.29 \\
\hline 10 & 16 & 0.95 & 0.0078 & 30.94 \\
\hline
\end{tabular}

\subsection{Role of Number and Location of Heat Pipes to Reduce Filling Time}

With multiple heat pipes, their relative location in the hydrogen storage tank becomes an additional parameter. In this study, we study one to four heat pipes to investigate their best positions in the tank. The mesh geometry of the tank with one heat pipe at its center is shown in Figure 18 with the hydrogen inlet port on its circumference. A heat pipe of $10 \mathrm{~mm}$ radius is placed in the center of a $100 \mathrm{~mm}$ radius tank. The pressure is fixed at 10 bar. The outer tank boundary is insulated as in the previous section. The convective heat transfer coefficient for the heat pipe used is the baseline value of $1600 \mathrm{~W} / \mathrm{m}^{2} \mathrm{~K}$. No $\mathrm{Al}$ foam is used in the tank. 


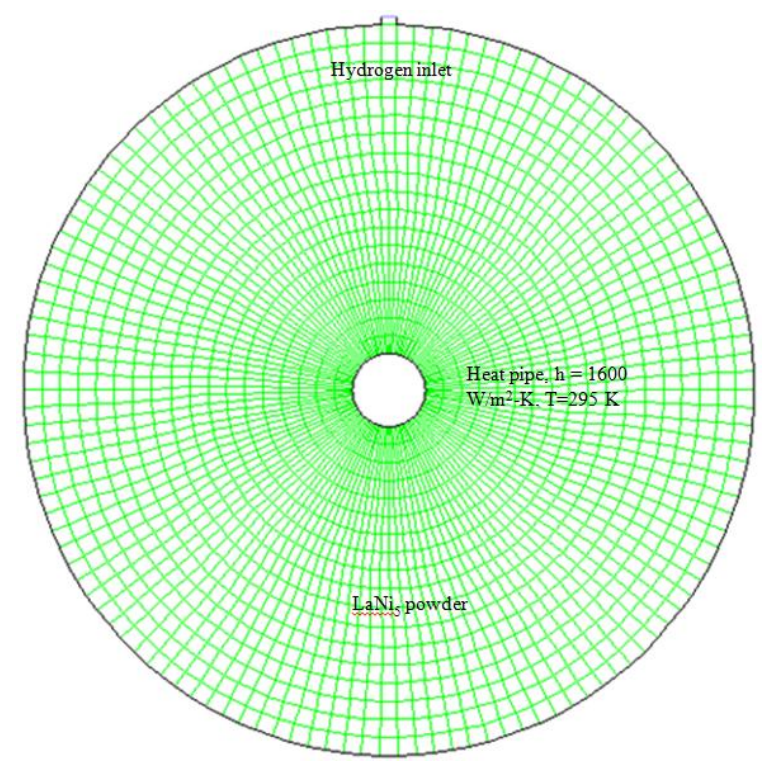

Figure 18 - Geometry of hydrogen storage tank of $100 \mathrm{~mm}$ radius incorporating one heat pipe of $10 \mathrm{~mm}$ radius

To perform comparative studies, we substituted the single $10 \mathrm{~mm}$ heat pipe with two heat pipes of $7.1 \mathrm{~mm}$ radius, three heat pipes of $5.8 \mathrm{~mm}$ radius, and four heat pipes of $5.0 \mathrm{~mm}$ radius. The radii were chosen such the total cross-sectional area of the heat pipes was identical in each case, i.e., the total volume of active hydride material did not change as the number of heat pipes was increased. The radius of the heat pipe for each case is listed in Table 6.

Table 6 - Heat pipe radius for one, two, three and four heat pipes

\begin{tabular}{|c|c|c|c|c|}
\hline Number of heat pipes & $\mathbf{1}$ & $\mathbf{2}$ & $\mathbf{3}$ & $\mathbf{4}$ \\
\hline Radius $(\mathrm{mm})$ & 10 & 7.1 & 5.8 & 5.0 \\
\hline
\end{tabular}




\subsubsection{Optimization Study without Al Foam}

Figure 19a shows the time to $90 \%$ saturation when two $7.1 \mathrm{~mm}$ heat pipes are placed in different arrangements. The saturation time is normalized by the time taken by one centrally-located $10 \mathrm{~mm}$ heat pipe. It is apparent that the optimal arrangement can significantly reduce saturation time. Similarly, Figures $19 b$ and $19 c$ show the normalized saturation times when three $5.8 \mathrm{~mm}$ heat pipes, and four $5.0 \mathrm{~mm}$ heat pipes, respectively, are placed at different locations. Saturation times are seen to vary significantly with pipe location.

Two topologies are possible when four heat pipes are employed. In one arrangement the four heat pipes are placed at the four corners of a square (Figure 19c), while in the other arrangement, one heat pipe is placed at the center of the tank, and the other three are placed on the vertices of an equilateral triangle (Figure 19d). Comparing the saturation times of the two geometries, we found the square geometry to be slightly superior as it reduces filling time by a maximum of $70 \%$, whereas the triangular geometry reduces filling time by $67 \%$ compared to the single heat pipe case. Overall, the best of these options is the case of four heat pipes located at the corners of a square whose vertices are $60 \mathrm{~mm}$ from the center. 


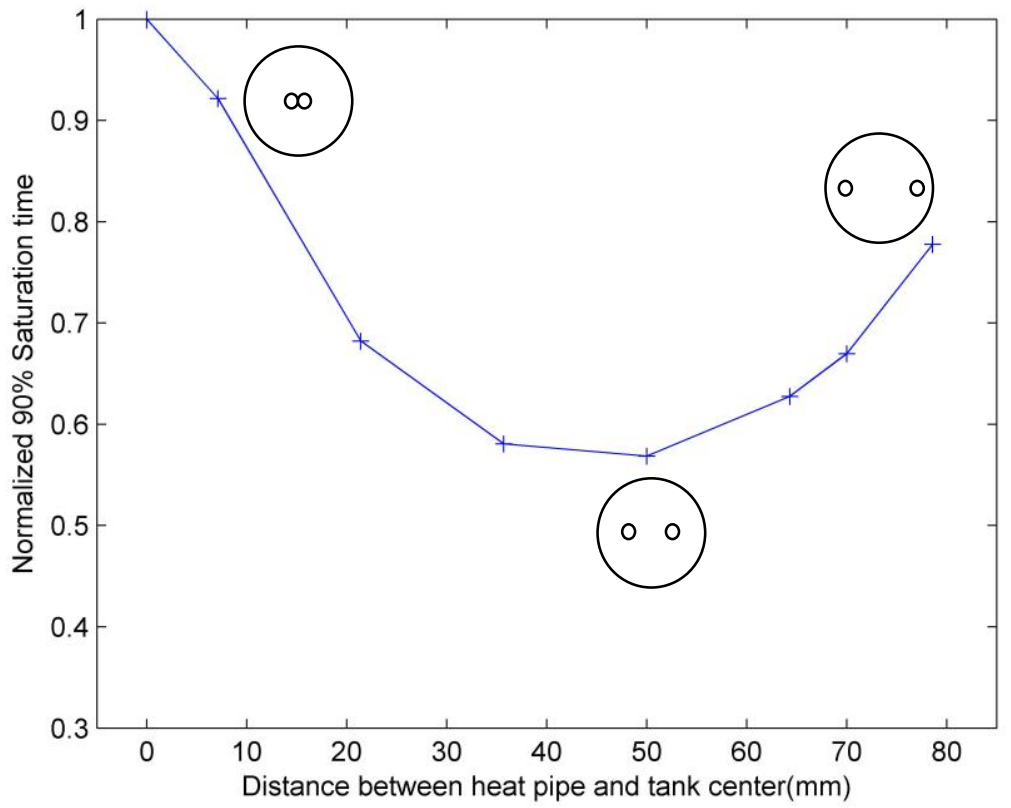

a.

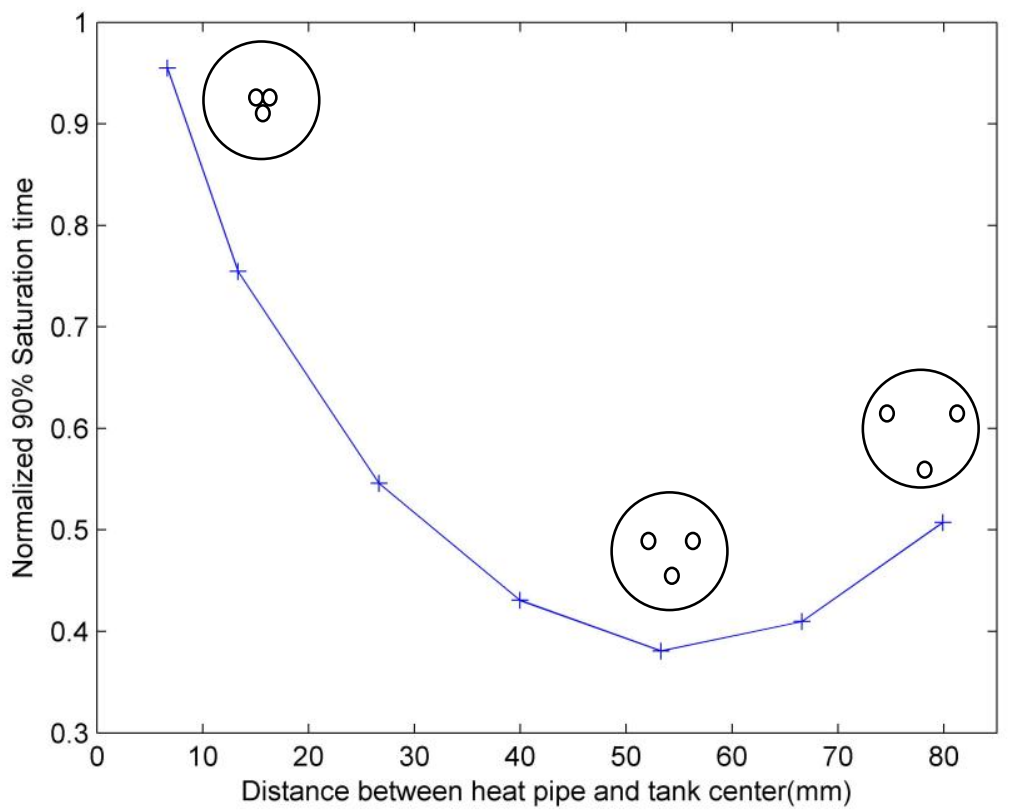

b. 


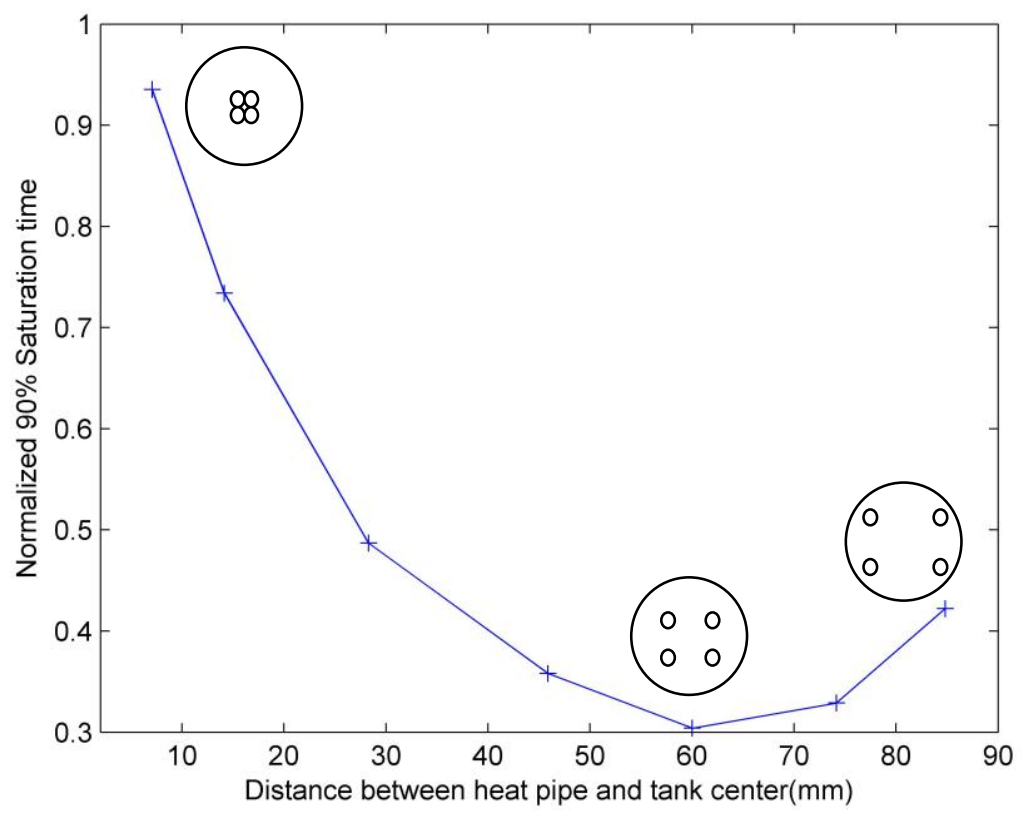

c.

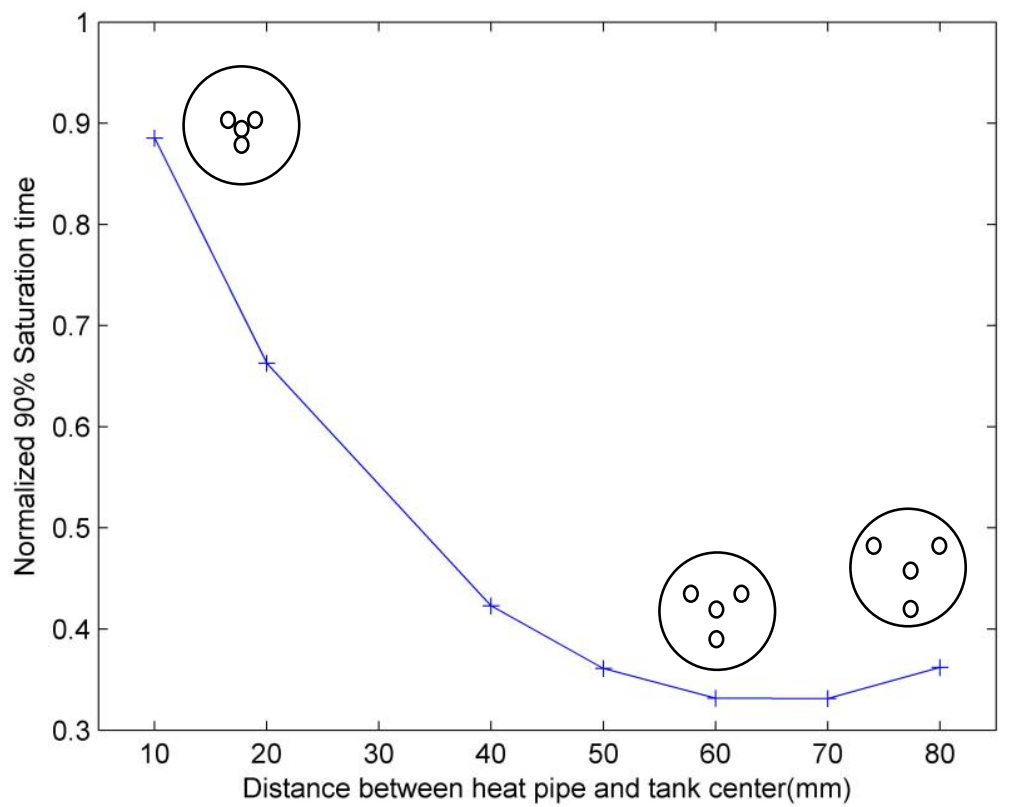

d.

Figure 19 - Normalized $90 \%$ saturation time for different positions of $10 \mathrm{~mm}$ heat pipes in a tank of $100 \mathrm{~mm}$ radius; (a) two heat pipes; (b) three heat pipes; (c) first configuration with four heat pipes; (d) second configuration with four heat pipes 
It is not surprising that adding more heat pipes while maintaining the same total pipe cross-sectional area reduces the filling time since the total heat transfer area in contact with the metal hydride bed increases as $\sqrt{N}$ where $N$ is the number of heat pipes. However, the results also show that their arrangement within the tank has a significant effect on the hydrogen absorption rate. The best position for each case is shown in Table 7.

Table 7 - Optimal charging time for one, two, three and four heat pipes

\begin{tabular}{|c|c|c|c|c|}
\hline Number of heat pipes & 1 & 2 & 3 & 4 \\
\hline Optimal charging time (s) & 84013 & 47770 & 31990 & 25545 \\
\hline Distance from the tank center & $0 \mathrm{~mm}$ & $50 \mathrm{~mm}$ & $54 \mathrm{~mm}$ & $60 \mathrm{~mm}$ \\
\hline
\end{tabular}

\subsubsection{Optimization Study with Al Foam}

The results in Figure 19 pertained to the case with no Al foam. The study was then repeated with 5\% and 10\% Al foam added to the tank. Since the best arrangement for $0 \% \mathrm{Al}$ foam has already been established, it was expedient to search for the new optimum in a small neighborhood of the original optimum with $0 \% \mathrm{Al}$ foam. Figure 20 shows that the optimal arrangement of heat pipes for the addition of $5 \%$ and $10 \%$ Al foam is identical to the one for $0 \% \mathrm{Al}$ foam. The saturation times are again normalized by the $90 \%$ saturation time for a single centrally-located heat pipe without $\mathrm{Al}$ foam. Note that the percentage enhancement of filling time with $5 \%$ and $10 \% \mathrm{Al}$ foam is different from the case with no Al foam in the hydride tank. 


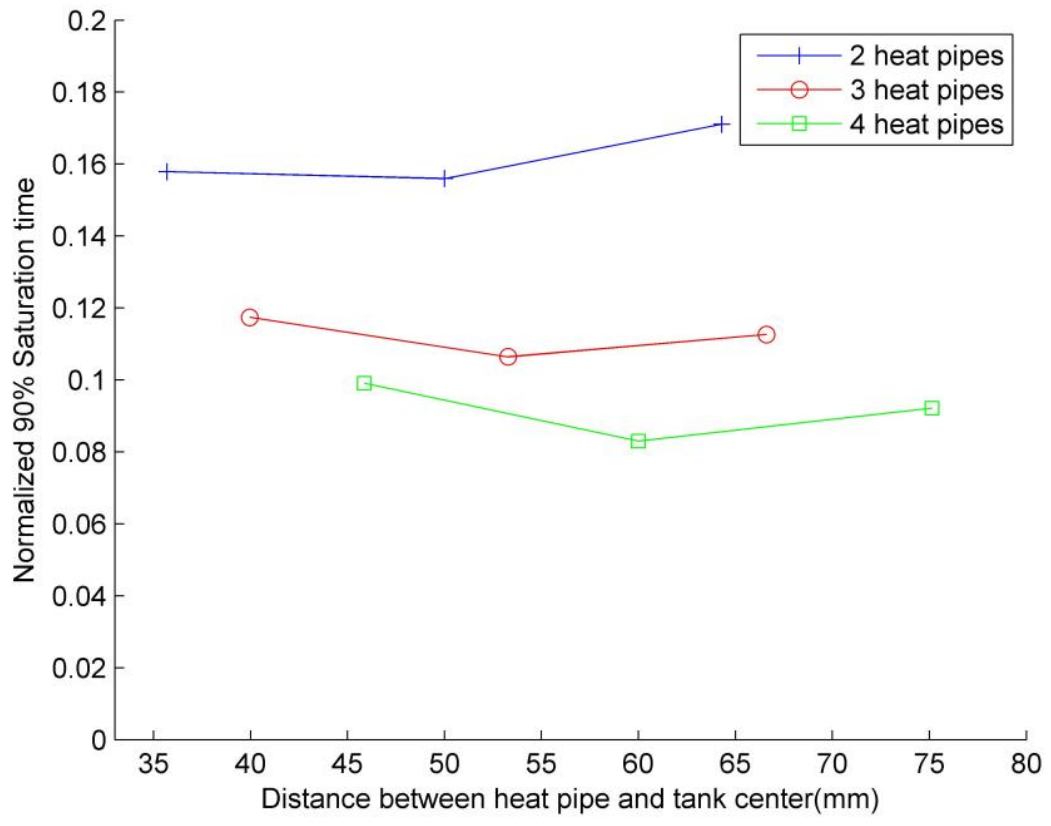

a.

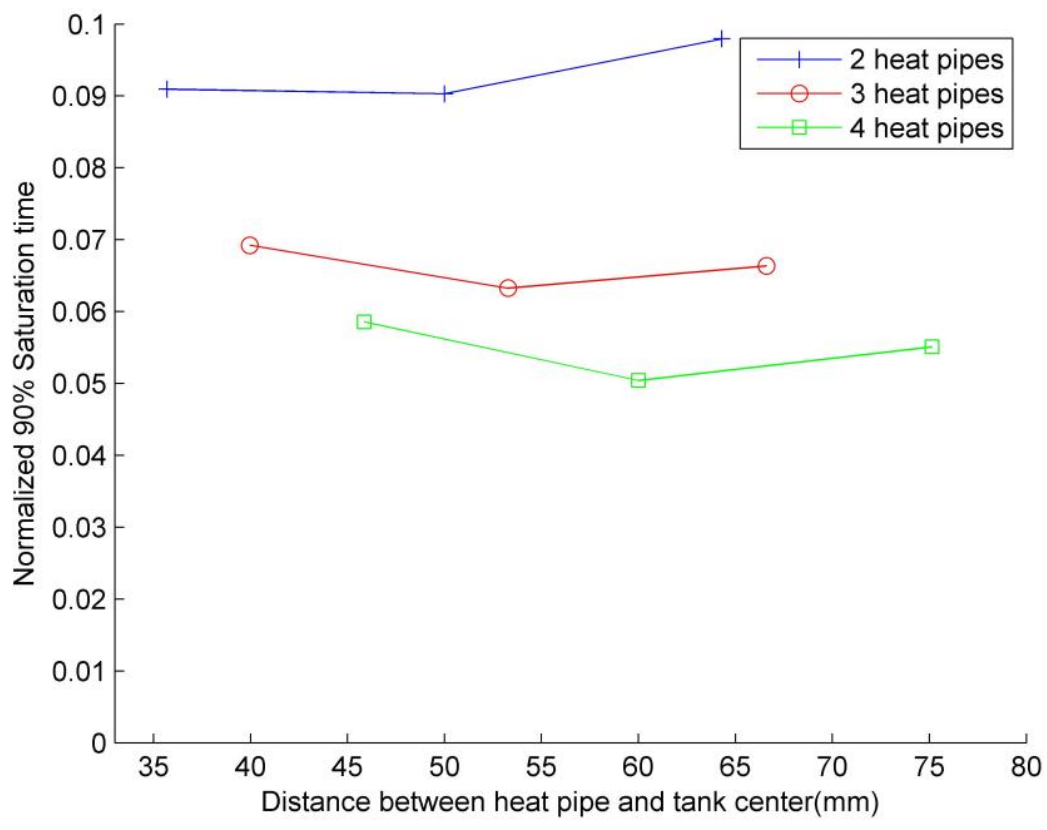

Figure 20 - Normalized 90\% saturation time for different arrangements of heat pipes with (a) $5 \%$, and (b) $10 \% \mathrm{Al}$ foam. For the four heat pipe case, only the square topology was employed 


\subsubsection{Optimization Study for Varying Tank Size without Al Foam}

To explore if the optimal heat pipe arrangement scales with tank size, we performed further studies with $25 \mathrm{~mm}$ and $50 \mathrm{~mm}$ radius tanks incorporating four heat pipes in a square topology. The heat pipe radius used was $5 \mathrm{~mm}$. The results in Figure 21 are normalized by the saturation time for a single centrally-located heat pipe having the same total cross-sectional area. The optimal radial locations for the heat pipes in the 25 and $50 \mathrm{~mm}$ radius tanks are approximately 15 and $30 \mathrm{~mm}$, respectively. For the original tank with $100 \mathrm{~mm}$ radius, the optimal radial distance of the heat pipes was 60 $\mathrm{mm}$ as seen from Figure 19c. Therefore, the optimal distance is seen to scale linearly with the tank size.

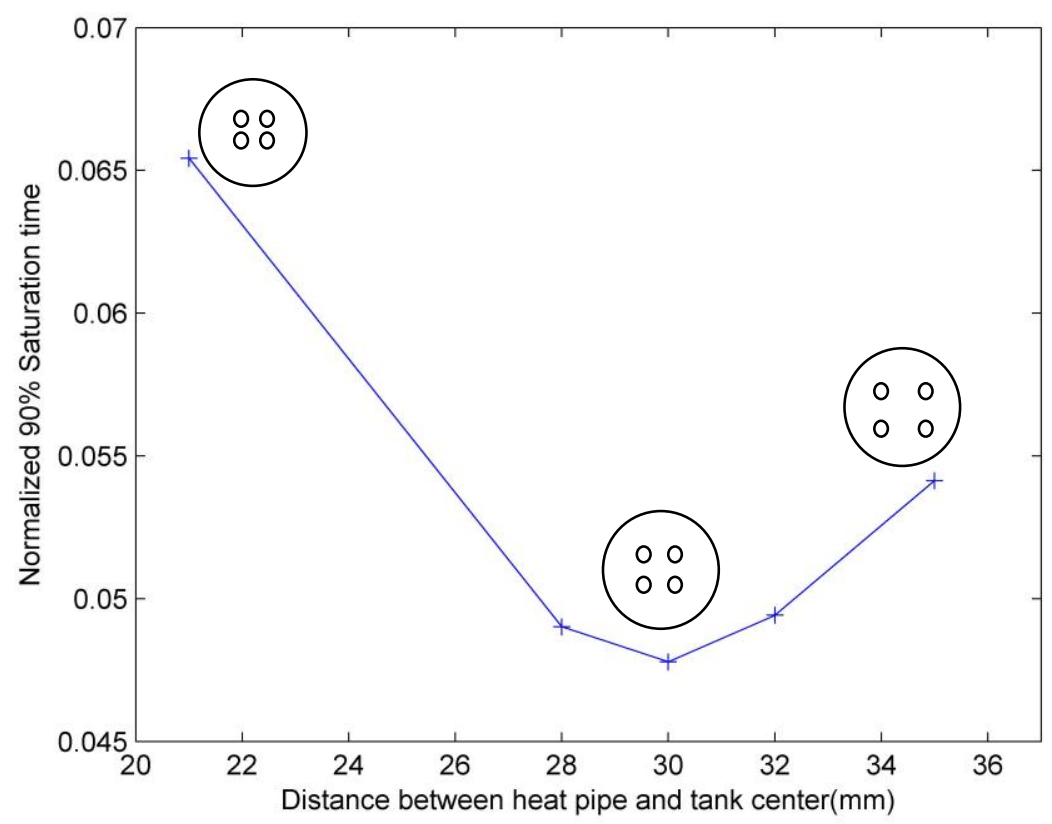

a. 


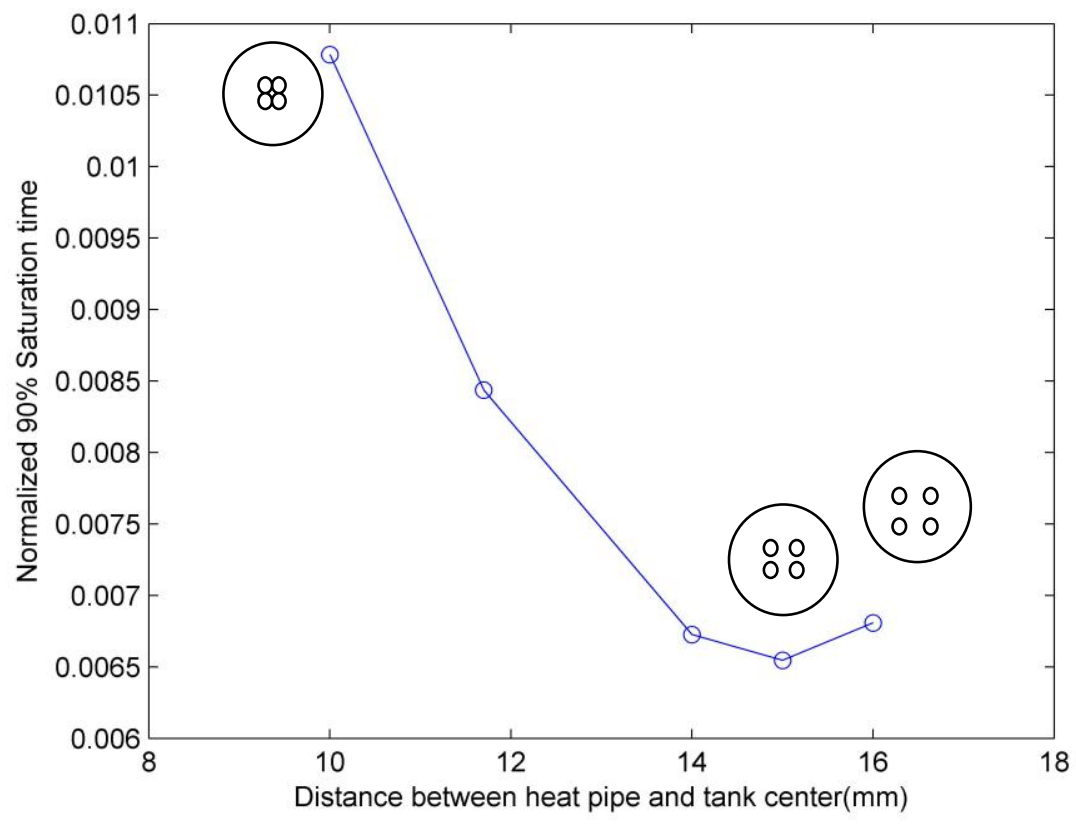

b.

Figure 21 - Normalized $90 \%$ saturation time for four heat pipes in a square topology in a tank of radius (a) $50 \mathrm{~mm}$, and (b) $25 \mathrm{~mm}$

\subsection{Summary}

In this chapter, we studied the optimization of heat pipe arrangement in a large hydrogen storage tank. First, we determined the radius of the $90 \%$ saturation area for a single heat pipe over range of heat pipe sizes, Al foam content, and charging time. The goal of this study was to determine the proper separation between multiple heat pipes to prevent overlapping of their saturation zones. $10 \% \mathrm{Al}$ foam is found to be an optimal content, since higher contents may reduce the size of the saturation zone for a given charging time as well as displace active hydride material from the tank.

Our study with up to four heat pipes showed that using more heat pipes of smaller radius is better than using fewer heat pipes with larger radius. The optimal configuration of heat pipes was also determined. It was found that the optimal 
configuration was not sensitive to the $\mathrm{Al}$ foam content. Finally, we found the optimal radial location of multiple heat pipes scaled linearly with tank size. 


\section{Chapter 5}

\section{CONCLUSIONS AND FUTURE WORK}

The transient simulation of hydrogen absorption in a cylindrical tank containing LaNi5 was conducted using Ansys Fluent 14.0. Heat was removed from the tank by incorporating one or more heat pipes within the tank, surrounding the tank with a water jacket, and adding Al foam to enhance the thermal conductivity of the hydride bed. The numerical model was validated by comparing with the experimental results of Chung et al [24]. Next, a parametric study was performed to investigate the role of various factors that can influence the charging time of hydrogen in the tank such as the convective heat transfer coefficients associated with the heat pipe and the cooling jacket, the cooling jacket temperature, the Al content of the hydride bed, the radii, location, number and arrangement of the heat pipes within the tank, and their relationship as the tank size is scaled-up. The parametric study revealed that the hydrogen charging rate can be enhanced by increasing the heat extraction rate from the hydride bed. This can be accomplished by increasing the convective heat transfer coefficient associated with the heat pipe and the water jacket but up to a certain point. The parametric study also showed that it was imperative to keep the water jacket temperature below $300 \mathrm{~K}$ to maintain an appreciable hydrogen absorption rate as dictated by the reaction kinetics of $\mathrm{LaNi}_{5}$. Addition of $\mathrm{Al}$ foam increased the effective thermal conductivity of the hydride bed and thus accelerated the heat removal rate

from the tank. However, as the added Al foam displaces active metal hydride from the 
tank, the optimal Al foam content will depend on the tank size and the desired saturation time.

For larger tanks, multiple heat pipes are required to reduce the saturation time from hours to minutes. This study revealed that it is not only the number of heat pipes but also their arrangement that can significantly reduce charging time. The addition of Al foam reduced the fill time but did not affect optimal arrangement of multiple heat pipes. The optimal radial location of the heat pipes were also found to scale linearly with the tank size. This parametric study shows that distributed cooling with heat pipes is a practical way to effectively remove heat during charging of hydride-based hydrogen storage tanks and thus reduce the hydrogen filling time.

Future work on hydride-based hydrogen storage tanks incorporating heat pipes may be conducted with three-dimensional mathematical models. Experiments could also be conducted to verify the simulation results provided in this study. 


\section{REFERENCES}

[1] Bak T, Nowotny J, Rekas M, Sorrell C C. Photo-electrochemical hydrogen generation from water using solar energy. Materials-related aspects. International Journal of Hydrogen Energy, 2002, 27(10): 991-1022.

[2] Li X. Principles of Fuel Cells. Taylor \& Francis Group, 2006.

[3] Targets for onboard hydrogen storage systems for light-duty vehicles (Rev. 4.0). US Department of Energy Office of Energy Efficiency and Renewable Energy and The Freedom CAR and Fuel Partnership, http://www1.eere.energy.gov/hydrogenandfuelcells/storage/pdfs/targets_onboard _hydro_storage_explanation.pdf; 2009.

[4] Dillon A C, Jones K M, Bekkedahl T A, Kiang C H, Bethune D S, Heben M J. Storage of hydrogen in single-walled carbon nanotubes. Nature, 1997, 386(6623): 377-379.

[5] Rosi N L, Eckert J, Eddaoudi M, Vodak D T, Kim J, O’Keefe M, Yaghi O M. Hydrogen storage in microporous metal-organic frameworks. Science, 2003, 300(5622): 1127-1129.

[6] Schlapbach L, Züttel A. Hydrogen-storage materials for mobile applications. Nature, 2001, 414(6861): 353-358.

[7] Sakintuna B, Lamari-Darkrim F, Hirscher M. Metal hydride materials for solid hydrogen storage: a review. International Journal of Hydrogen Energy, 2007, 32(9): 1121-1140. 
[8] Hirscher M, Becher M. Hydrogen storage in carbon nanotubes. Journal of Nanoscience and Nanotechnology, 2003, 3(1-2): 1-2.

[9] Nasrallah S B, Jemni A. Heat and mass transfer models in metal-hydrogen reactor. International Journal of Hydrogen Energy, 1997, 22(1): 67-76.

[10] Inomata A, Aoki H, Miura T. Measurement and modelling of hydriding and dehydriding kinetics. Journal of Alloys and Compounds, 1998, 278(1): 103-109.

[11] Jemni A, Nasrallah S B, Lamloumi J. Experimental and theoretical study of ametal-hydrogen reactor. International Journal of Hydrogen Energy, 1999, 24(7): 631-644.

[12] Kaplan Y, Veziroglu T N. Mathematical modelling of hydrogen storage in a LaNi5 hydride bed. International Journal of Energy Research, 2003, 27(11): 1027-1038.

[13] Nakagawa T, Inomata A, Aoki H, Miura T. Numerical analysis of heat and mass transfer characteristics in the metal hydride bed. International Journal of Hydrogen Energy, 2000, 25(4): 339-350.

[14] Levesque S, Ciureanu M, Roberge R, Motyka Theodore. Hydrogen storage for fuel cell systems with stationary applications-I. Transient measurement technique for packed bed evaluation. International Journal of Hydrogen Energy, 2000, 25(11): 1095-1105.

[15] Chen Y, Sequeira Cesar A C, Chen C, Wang X, Wang Q. Metal hydride beds and hydrogen supply tanks as minitype PEMFC hydrogen sources. International Journal of Hydrogen Energy, 2003, 28(3): 329-333. 
[16] Wang H, Prasad A K, Advani S G. Hydrogen storage systems based on hydride materials with enhanced thermal conductivity. International Journal of Hydrogen Energy, 2012, 37(1): 290-298.

[17] Oi T, Maki K, Sakaki Y. Heat transfer characteristics of the metal hydride vessel based on the plate-fin type heat exchanger. Journal of Power Sources, 2004, 125(1): 52-61.

[18] Wang H, Prasad A K, Advani S G. Hydrogen storage system based on hydride materials incorporating a helical-coil heat exchanger. International Journal of Hydrogen Energy, 2012.

[19] Raju M, Kumar S. Optimization of heat exchanger designs in metal hydride based hydrogen storage systems. International Journal of Hydrogen Energy, 2012, 37(3): 2767-2778.

[20] Garrison S L, Hardy B J, Gorbounov M B, Tamburello D A, Corgnale C, Van Hassel B A, Mosher D A, Anton D. Optimization of internal heat exchangers for hydrogen storage tanks utilizing metal hydrides. International Journal of Hydrogen Energy, 2012, 37(3): 2850-2861.

[21] Vasiliev L L, Kanonchik L E, Kulakov A G, Babenko V A. Hydrogen storage system based on novel carbon materials and heat pipe heat exchanger. International Journal of Thermal Sciences, 2007, 46(9): 914-925.

[22] Mozumder A K, Chowdhury M S H, Akon A F. Characteristics of Heat Transfer for Heat Pipe and Its Correlation. ISRN Mechanical Engineering, 2011, 2011(2011):1-7. 
[23] Boo J H, Park Y H, Katsuta M, Bae S C. Numerical analysis of a metal hydride reactor with embedded heat pipes to enhance heat transfer characteristics. In: ASME CONF PROC HT2009-88454. p. 409-416.

[24] Chung C A, Yang S W, Yang C Y, Hsu C W, Chiu P Y. Experimental study on the hydrogen charge and discharge rates of metal hydride tanks using heat pipes to enhance heat transfer. Applied Energy, 2013,103:581-587.

[25] Fluent Inc. User's guide for FLUENT Version 6.3.26. Fluent Inc., 2006.

[26] Catlin G. PEM fuel cell modeling and optimization using a genetic algorithm. University of Delaware, 2010.

[27] Fluent Inc. User's guide for GAMBIT Version 2.4.6. Fluent Inc., 2000.

[28] Jemni A, Nasrallah S B. Study of two-dimensional heat and mass transfer during absorption in a metal-hydrogen reactor. International Journal of Hydrogen Energy, 1995, 20(1): 43-52.

[29] MacDonald BD, Rowe AM. Impacts of external heat transfer enhancements on metal hydride storage tanks. International Journal of Hydrogen Energy, 2006, 31(12): 1721-1731. 